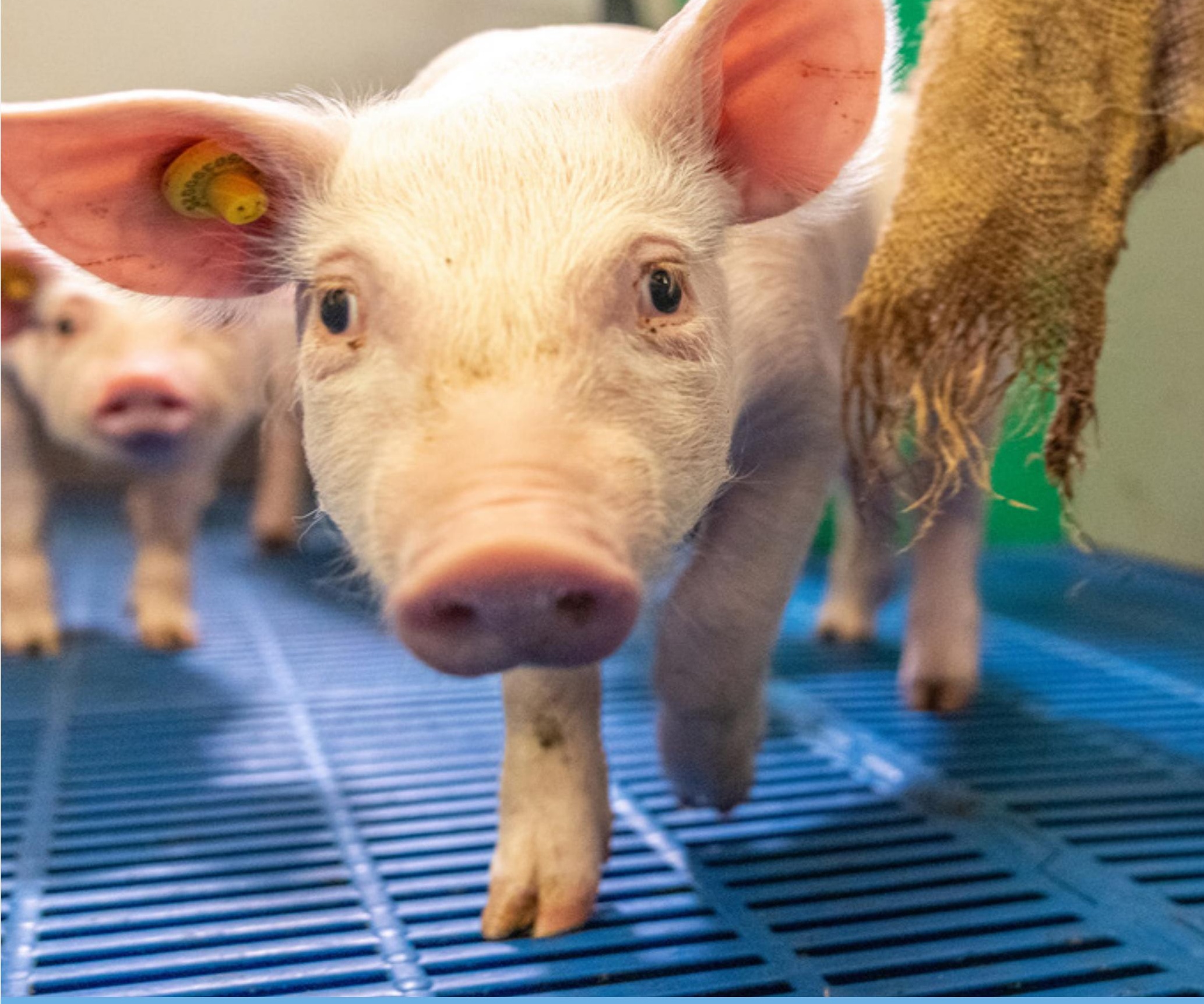

\title{
Amino acid and energy requirements of weaned piglets kept under low and high sanitary conditions
}

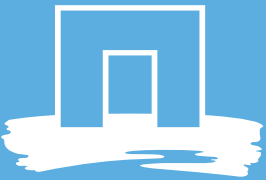





\title{
Amino acid and energy requirements of weaned piglets kept under low and high sanitary conditions
}

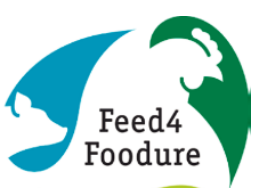 \\ C.M.C. van der Peet-Schwering ${ }^{1}$, M. van Helvoort ${ }^{2}$, B. Martens ${ }^{3}$, A.J.M. Jansman ${ }^{1}$ \\ ${ }^{1}$ Wageningen Livestock Research; ${ }^{2}$ De Heus Animal Nutrition B.V.; ${ }^{3}$ Agrifirm
}

This research was conducted by Wageningen Livestock Research as part of the Public Private Partnership "Feed4Foodure" (TKI-AF-16123), and funded by Vereniging Diervoederonderzoek Nederland (VDN) and the Ministry of Agriculture, Nature and Food Quality (LNV) 
C.M.C. van der Peet-Schwering, M. van Helvoort, B. Martens, A.J.M. Jansman, 2021. Amino acid and energy requirements of weaned piglets kept under low and high sanitary conditions. Wageningen Livestock Research, Public Report 1319.

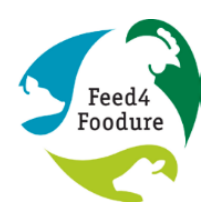

This report can be downloaded for free at https://doi.org/10.18174/547439 or at www.wur.nl/livestock-research (under Wageningen Livestock Research publications).

\section{(cc) BY-NC}

This work is licensed under a Creative Commons Attribution-Non Commercial 4.0 International License.

(C) Wageningen Livestock Research, part of Stichting Wageningen Research, 2021

The user may reproduce, distribute and share this work and make derivative works from it. Material by third parties which is used in the work and which are subject to intellectual property rights may not be used without prior permission from the relevant third party. The user must attribute the work by stating the name indicated by the author or licensor but may not do this in such a way as to create the impression that the author/licensor endorses the use of the work or the work of the user. The user may not use the work for commercial purposes.

Wageningen Livestock Research accepts no liability for any damage resulting from the use of the results of this study or the application of the advice contained in it.

Wageningen Livestock Research is ISO 9001:2015 certified.

All our research commissions are in line with the Terms and Conditions of the Animal Sciences Group. These are filed with the District Court of Zwolle.

Public Wageningen Livestock Research Report 1319 


\section{Table of contents}

$\begin{array}{ll}\text { Foreword } & 5\end{array}$

$\begin{array}{ll}\text { Summary } & 7\end{array}$

1

$\begin{array}{ll}\text { Introduction } & 9\end{array}$

2

$\begin{array}{ll}\text { Material and methods } & 10\end{array}$

2.1 Animals 10

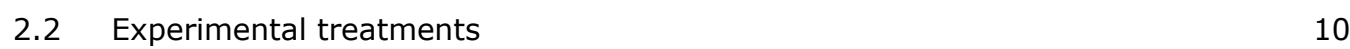

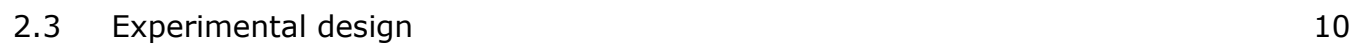

2.4 Housing and climate 11

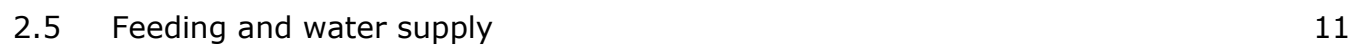

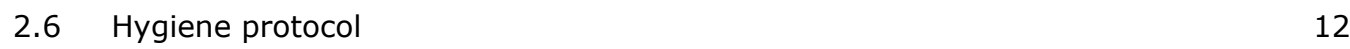

2.7 Measurements 13

$\begin{array}{lll}2.8 & \text { Statistical analysis } & 14\end{array}$

3

$\begin{array}{ll}\text { Results } & 15\end{array}$

3.1 Diets $\quad 15$

3.2 Performance $\quad 15$

$\begin{array}{lll}3.3 & \text { Health and faecal scores } & 21\end{array}$

$\begin{array}{lll}3.4 & \text { Blood parameters } & 24\end{array}$

$\begin{array}{llr}4 & \text { Discussion } & 26\end{array}$

$5 \quad$ Conclusions $\quad 31$

$\begin{array}{ll}\text { References } & 33\end{array}$

Appendix 1 Starting points to calculate the increased energy and SID EAA levels $\quad 35$

Appendix 2 Composition of the experimental diets 38

Appendix 3 Analysed nutrient composition of the experimental diets $(\mathrm{g} / \mathrm{kg}) 42$

$\begin{array}{lll}\text { Appendix } 4 & \text { Room temperature } & 43\end{array}$ 


\section{Foreword}

Feed4Foodure is a public-private partnership between the Dutch Ministry of Agriculture, Nature and Food Quality (LNV), Vereniging Diervoederonderzoek Nederland (VDN) and Wageningen Livestock Research. Feed4Foodure aims to contribute to sustainable and healthy livestock farming in the Netherlands, simultaneously strengthening its competitive position on the global market.

In the Feed4Foodure program line "Improvement of the utilization of nitrogen in pigs" research is conducted to improve resource and protein efficiency in pigs. This report presents the results of a study performed by Wageningen Livestock Research and the private partners De Heus Animal Nutrition B.V. and Agrifirm on the effects of increased levels of dietary energy and amino acids on the growth performance of weaned piglets kept under low or high sanitary conditions.

The authors thank LNV and VDN for their support and the members of the Cluster "Swine" for their valuable input in the study. The skilful and devoted contribution of staff of the two facilities (Swine Nutrition Center (SNC) De Elsenpas and Research Farm Laverdonk) at which the research was conducted, and of colleagues involved at De Heus and Agrifirm is highly appreciated!

Alfons Jansman, project leader 


\section{Summary}

The aim of the present study was to evaluate the effects of increased levels of dietary energy and essential amino acids (EAA), related to the assumed increased EAA and energy requirements in immune stimulated pigs, on the growth performance of weaned piglets under low sanitary conditions (LSC), in which the immune system of the pigs was supposed to be activated, or under high sanitary conditions (HSC) resulting in an expected lower state of activation of the immune system. The trial was conducted on two farms. On Farm A, the trial was conducted with 689 weaned piglets (Tempo boar $x$ Topigs Norsvin 70 sow). On Farm B, the trial was conducted with 768 weaned piglets (Tempo boar $x$ Topigs Norsvin 70 sow). Piglets were weaned and assigned to the trial at an age of four weeks and followed till five weeks after weaning. In a $2 \times 3 \times 2$ (Farm A) or $2 \times 4 \times 2$ (Farm B) factorial design, piglets were allocated to:

1) Sanitary conditions: high sanitary conditions (HSC) or low sanitary conditions (LSC).

2) Energy level and $A A$ level and profile:

a) Farm A: 1) control diet; 2) increased levels of standardized ileal digestible (SID) AA; 3) increased levels of energy and SID AA (Lys, Met, Thr, Trp, Val and Ile).

b) Farm B: 1) control diet; 2) increased levels SID AA; 3) increased level of energy; 4) increased levels of energy and SID AA (Lys, Met, Thr, Trp, Val and Ile).

3) Sex: boars or gilts.

A contrast in sanitary conditions was created by imposing the piglets to differences in strategy for vaccination against a number of pathogens, cleaning protocol of the facility and hygiene protocol applied during the study. Moreover, there was a difference in room temperature between the LSC and HSC rooms. The levels of supplementation of EAA and energy in the experimental diets were based on a model that calculates the effects of low sanitary conditions on the EAA and energy requirements of pigs. Boars and gilts were housed separately. Piglets were fed a weaner diet from weaning till day 9 after weaning and a starter diet from day 9 till day 35 after weaning. Diets were supplied ad libitum in a dry feed hopper with two feeding places. In all pens, 6 or 8 piglets were housed.

The main conclusions of the study are:

Sanitary conditions:

- Despite the contrast in cleaning-, vaccination- and hygiene protocol, based on blood serology no or only very small differences in degree of activation of the immune system between HSC and LSC pigs were observed.

- $\quad$ From weaning till day 35 after weaning, ADG and ADFI were similar in HSC and LSC piglets on Farm A. On Farm B, the HSC piglets showed a numerically $8.6 \%$ higher ADG (516 vs $475 \mathrm{~g} / \mathrm{d}$ ) and $3 \%$ higher ADFI ( 0.71 vs $0.69 \mathrm{~kg} / \mathrm{d}$ ). Feed conversion ratio was $4 \%$ lower (1.32 vs 1.37 ) in HSC piglets than in LSC piglets on Farm A and 5.5\% lower (1.38 vs 1.46$)$ on Farm B.

- Sanitary conditions did not affect the number of culled piglets. The number of veterinary treated piglets did not differ between HSC and LSC piglets on Farm A. On Farm B, however, the number of piglets that was veterinary treated due to leg problems was higher in HSC piglets. The occurrence of diarrhea was higher in LSC piglets than in HSC piglets on both farms, especially in week 1 after weaning.

Increased amino acid content:

- $\quad$ An increase in dietary EAA content for Lys, Met, Thr, Trp, Val and Ile improved ADG and FCR in both LSC and HSC piglets. However, it only slightly decreased the difference in ADG and FCR between LSC and HSC piglets. This applies to both farms. 


\section{Increased energy content:}

- $\quad$ An increase in only energy level did not improve the performance of both LSC and HSC piglets. The increase in dietary energy level did not increase the average daily energy intake ( $A D E I$ ) but reduced the ADFI resulting in an impaired ADG and energy conversion ratio (ECR).

Increased energy and amino acid content:

- $\quad$ An increase in both EAA and energy level increased ADG (437 vs $416 \mathrm{~g} / \mathrm{d}$ ) and ADEI (0.73 vs $0.67 \mathrm{EW} / \mathrm{d}$ ) compared to the control group in LSC piglets on Farm A, but did not affect ADG and ADEI in HSC piglets.

- On Farm B, an increase in both EAA and energy level did not improve ADEI and ADG compared to the control diet in both LSC and HSC piglets.

- On both farms, feed conversion ratio was improved but ECR was impaired in piglets fed the energy and AA supplemented diets compared to the control group. The effects on FCR and ECR were similar in LSC and HSC pigs.

- Dietary supplementation of both EAA and energy was no more or even less effective in increasing performance in both LSC and HSC piglets than dietary supplementation of EAA alone. This applies to both farms.

Overall, it can be concluded that an increase in contents of only dietary EAA (Lys, Met, Thr, Trp, Val and Ile) improved ADG and FCR in both LSC and HSC piglets. It only slightly decreased, however, the difference in ADG and FCR between LSC and HSC piglets. These results suggest that the SID AA recommendations of CVB (2020) for piglets (9.2 g SID lysine/EW) may be below the actual requirements for maximum growth performance of piglets, also under high sanitary conditions. An increase in only dietary energy level did not improve the performance of both LSC and HSC piglets. Dietary supplementation of both EAA and energy was equally or even less effective in increasing performance in both LSC and HSC piglets than dietary supplementation of EAA alone. 


\section{Introduction}

Large variation in performance of weaned piglets and growing-finishing pigs (GF) exists between commercial pig farms (Agrovision, 2017). The health status of pigs is one of the major factors contributing to this large variation in pig performance (Van der Peet-Schwering et al., 2019). Variation in health status exists between farms but also amongst individual pigs within farms, as e.g. indicated by variation in serum concentrations of acute phase proteins that was correlated to the occurrence of disease or presence of lesions as a result of tail or ear biting (Petersen et al., 2002; Piñeiro et al., 2009; Piñeiro et al., 2013). In commercial pig farms, pigs are continuously exposed to (non-) pathogenic agents, which can activate the immune system. During immune system stimulation (ISS), nutrients are redistributed from anabolic and maintenance processes towards processes involved in immunity and disease resistance (Klasing and Johnstone, 1991; Spurlock, 1997).

Van der Meer et al. (2016) performed a study with growing-finishing pigs to determine the effects of two dietary amino acid (AA) profiles (basal profile and supplemented profile with increased levels of methionine, threonine and tryptophan, considering increased AA requirements under conditions of low sanitary status and activation of the immune system) and sanitary status of pigs and their interaction on energy and protein metabolism. Results of this study showed that AA requirements are dependent on sanitary conditions. Supplementation of diets with particular essential AA improved growth performance, especially under low sanitary status conditions. Despite additional supplementation of some essential amino acids (EAA), growth performance of the pigs under low sanitary conditions (LSC) was still lower compared to pigs kept under high sanitary conditions (HSC). It might be assumed that supplementation of EAA under LSC is only supporting body protein retention and body weight gain if dietary energy intake is not limiting growth performance. Therefore, Van der Peet-Schwering et al. (2020) performed a study in GF pigs to evaluate the effects of an increased energy and EAA contents in the diet, related to the assumed increased amino acid and energy requirements in immune stimulated pigs (Van der Peet-Schwering et al., 2019), on the growth performance of GF pigs. The diets were evaluated in pigs kept under a low or high sanitary status regime assumed to create a contrast in degree of immune system activation in the pigs. The results of the study showed that an increase in contents of dietary energy and EAA (Lys, Met, Thr, Trp, Val and Ile) increased growth performance and energy intake more in LSC than in HSC pigs. This suggests opportunities to at least partly compensate for the reduction in growth performance in GF pigs kept under low sanitary conditions and/or sub-optimal health condition by modification of the nutrient composition of the diet. Increasing energy density of the diet and increasing dietary concentrations of selected EAA, possibly will also compensate for the reduction in growth performance in weaned piglets kept under low sanitary conditions and/or sub-optimal health condition compared to weaned piglets under high sanitary conditions.

Therefore, we performed a study to evaluate the effects of increased levels of dietary energy and essential AA (via additional supplementation of free AA and increase of dietary energy density) on the growth performance of weaned piglets under LSC, in which the immune system of the pigs was supposed to be activated, or under HSC resulting in an assumed lower state of activation of the immune system. The contrast in dietary AA level and profile and energy level of the diets was based on model calculations as described in the desk study "Amino acid requirements in relation to health in growing and finishing pigs" (Van der Peet-Schwering et al., 2019). As sanitary, environmental and management conditions vary largely among farms the research was carried at two experimental farms, allowing to evaluate differences in responses to diet modification among farms.

Via the present study, the model calculations as described by Van der Peet-Schwering et al. (2019) can be validated for weaned piglets and knowledge is developed which will allow the pig production sector and the feed industry to more precisely match nutrient composition of the diet and feeding strategy with the nutritional requirements of pigs under a variety of sanitary and health conditions as encountered in practice. 


\section{Material and methods}

\section{$2.1 \quad$ Animals}

The trial was conducted at two farms:

- Farm A: Swine Research Facility Laverdonk of Agrifirm;

- Farm B: Swine Nutrition Center (SNC) De Elsenpas of De Heus.

On Farm A, the trial was conducted with 689 weaned piglets (Tempo boar $\mathrm{x}$ Topigs Norsvin 70 sow). Piglets were assigned to the trial in four batches with three weeks in between. Piglets were weaned at the age of four weeks and followed till five weeks after weaning. On Farm B, the trial was conducted with 768 weaned piglets (Tempo boar $x$ Topigs Norsvin 70 sow). Piglets were assigned to the trial in two batches with six weeks in between. Piglets were weaned at the age of four weeks and followed till five weeks after weaning. The trial was conducted from July till October 2020.

\subsection{Experimental treatments}

In a $2 \times 3 \times 2$ (Farm A) or $2 \times 4 \times 2$ (Farm B) factorial design, piglets were allocated to:

1) Sanitary conditions: high sanitary conditions (HSC) or low sanitary conditions (LSC).

2) Energy level and $A A$ level and profile:

a) Farm A: 1) control diet; 2) increased levels of standardized ileal digestible (SID) AA; 3) increased levels of energy and SID AA.

b) Farm B: 1) control diet; 2) increased levels SID AA; 3) increased level of energy; 4) increased levels of energy and SID AA.

3) Sex: boars or gilts.

Piglets had ad libitum access to the diets. Boars and gilts were housed seperately.

\subsection{Experimental design}

\section{Suckling piglets}

In the nursery room, half of the male and female piglets within a litter was vaccinated against Mycoplasma hyopneumonia and PRRS (Farm A) or PCV2 and PRRS (Farm B) one week before weaning (litter 1: the male and female piglet with the highest birth weight were vaccinated, the second heaviest piglets were not vaccinated, the third heaviest piglets were vaccinated etc.; litter 2: the male and female piglet with the highest birth weight were not vaccinated, the second heaviest piglets were vaccinated, the third heaviest piglets were not vaccinated, etc.).

\section{Weaned piglets}

At an age of four weeks, the piglets were weaned and allotted to the HSC or LSC treatment based on vaccination regime in the nursery room and body weight at weaning. The vaccinated piglets were allotted to the HSC treatment and the non-vaccinated piglets to the LSC treatment. Boars and gilts were housed separately. Within sanitary conditions there were low weight, medium weight and heavy body weight blocks. Each block consisted of three (Farm A) or four (Farm B) pens with boars or three or four pens with gilts. Each pen within a block was assigned to one of the three or four dietary treatments. Only healthy piglets weighing $5 \mathrm{~kg}$ or more at weaning were assigned to the trial. On Farm $A$, in total 114 pens ( 2 sanitary status $\times 3$ dietary treatments $\times 2$ sexes $\times 9$ or 10 replicates) were assigned to the experiment. On Farm $B$, in total 128 pens ( 2 sanitary status $x 4$ dietary treatments $\times 2$ sexes $\times 8$ replicates) were assigned to the experiment. HSC and LSC piglets were housed in separate rooms. Each room had separate manure pits and separate ventilation regulation. 
The HSC rooms were intensively cleaned in four steps before the pigs were moved to the rooms: 1 ) cleaning the room (including ceiling, feeding hoppers and drinking trough) with water; 2) foaming with a soaking agent; 3 ) high pressure washing; 4) disinfecting. The HSC rooms and the floors in the pens were dry before the piglets were moved to the pens. On Farm $\mathrm{A}$, the room temperature was $31^{\circ} \mathrm{C}$ at the day of weaning and gradually decreased to $24^{\circ} \mathrm{C}$ at day 35 after weaning. On Farm $\mathrm{B}$, the room temperature was $28^{\circ} \mathrm{C}$ on the day of weaning and gradually decreased to $23^{\circ} \mathrm{C}$ at day 35 after weaning. A strict hygiene protocol (see chapter 2.6) was used when entering the HSC rooms.

The LSC rooms were not cleaned after a previous batch of weaned piglets left the room and no hygiene protocol was used when entering the rooms. The floor in the pens and the corridor was wetted 24 hours before the piglets were moved to the pens in order to increase the humidity in the room. The room temperature was $23^{\circ} \mathrm{C}$ from the day of weaning till day 35 after weaning. Moreover, in week 2 and 4 after weaning, faeces from other pigs at the farm (faeces from growing-finishing pigs on Farm $A$ and a mix of faeces of weaned piglets and growing-finishing pigs on Farm B) was spread in the LSC pens to enhance the contrast in sanitary status between treatments. On Farm A, each time 150 gram faeces per piglet was spread per LSC pen. On Farm B, the faeces were mixed with water. Each time 0.5 litre per piglet was spread on the solid floor per LSC pen.

\subsection{Housing and climate}

\section{Farm A}

The HSC weaned piglets were housed in ten rooms (two rooms in batch 1, 3 and 4, and three rooms in batch 2). The LSC weaned piglets were housed in ten other rooms (two rooms in batch 1,3 and 4, and three rooms in batch 2). The HSC and LSC rooms in batch 1 and 3 had each eight pens (six pens per room were used for the trial) with 8 piglets per pen. The HSC and LSC rooms in batch 2 and 4 had each six pens with 6 piglets per pen. The pens with 8 piglets were $2.85 \times 1.30 \mathrm{~m}\left(0.46 \mathrm{~m}^{2}\right.$ space/piglet) and had a plastic coated fully slatted floor. The pens with 6 piglets were $2.56 \times 1.26 \mathrm{~m}$ ( $0.54 \mathrm{~m}^{2}$ space/piglet) and had a plastic coated fully slatted floor (in two HSC rooms and two LSC rooms) or a $40 \%$ concrete solid floor with $60 \%$ slats (in one HSC room and one LSC room). The climate in the rooms was controlled by computer and an automatic curve, as described in chapter 2.3. From 7.00 till $18.00 \mathrm{~h}$, the rooms were illuminated with artificial light (automatically by a timer). A chain with a PVC ball, a burlack sack and a rope were supplied in every pen as pen enrichment.

\section{Farm B}

The HSC weaned piglets were housed in two rooms with each 32 pens (one room in batch 1 and one room in batch 2). The LSC weaned piglets were housed in two other rooms with each 32 pens (one room in batch 1 and one room in batch 2). In all pens, 6 piglets were housed. The pens were $2.55 \mathrm{x}$ $1.20 \mathrm{~m}$ ( $0.44 \mathrm{~m}^{2}$ space/piglet) and had $40 \%$ concrete solid floor and $60 \%$ composite slatted floor. The climate in the rooms was controlled by computer and an automatic curve, as described in chapter 2.3. From 7.00 till $17.00 \mathrm{~h}$, the rooms were illuminated with artificial light (automatically by a timer). A rope was supplied in every pen as pen enrichment.

\subsection{Feeding and water supply}

From weaning till day 9 after weaning, piglets were fed ad libitum a weaner diet in a dry feed hopper with two feeding places. Besides, on Farm A, during the first five days after weaning, the weaner diet was supplied two times a day in a round bowl per pen. From day 9 till day 35 after weaning, piglets were fed ad libitum a starter diet in a dry feed hopper with two feeding places. The weaner and starter diets were provided as pellets via a computerized automatic system, which registered the amount of feed (in kg) supplied per pen per day. Drinking water was supplied ad libitum via a drinking bowl in the pen.

The control weaner diet and the control starter diet were practice-based diets and met the nutritional requirements (CVB, 2020). The levels of supplementation of EAA and energy in the experimental diets were based on the use of a calculation model as described by van der Peet-Schwering et al. (2019) in 
the report entitled "Amino acid requirements in relation to health status in growing and finishing pigs". Using a factorial approach for calculating requirements for body protein and energy deposition, the effects of "low sanitary conditions" on the EAA and energy requirements of pigs were estimated and translated to adjusted optimal dietary energy and EAA levels. The scenario "low sanitary conditions" as used in the calculations included effects related to feed intake, ileal digestibility of $A A$, additional requirements for $A A$ for maintenance purposes, reduction of post absorptive efficiency of $A A$, maximum protein deposition capacity and increase in maintenance requirement for energy. The starting points for the calculation of the increased energy and SID EAA levels are described in Appendix 1. The control diets were formulated to contain EAA relative to energy as advised by CVB (2020). The energy value (EW) of the control diets was 1.15. The SID lysine level in the weaner and starter control diets were 10.65 and $10.58 \mathrm{~g} / \mathrm{kg}$, respectively. The calculated dietary adjustments for EAA and energy in the weaner and starter diet are presented in Table 1 and in Appendix 1. As L-Leu and L-His are not largely available in free form for application in commercial diets, the concentrations of both amino acids on an SID basis were not included/taken into account in the adjusted diets although the model calculations indicated a deficiency for these amino acids in the scenario of low sanitary conditions.

Table 1 Absolute increase in concentration of essential amino acids ( $\mathrm{g}$ SID/ $\mathrm{kg}$ ) and energy $(E W / \mathrm{kg})$ in the supplemented weaner and starter diets compared to the control diets.

\begin{tabular}{lcc} 
& Weaner diet & Starter diet \\
Lys & 1.00 & 0.89 \\
\hline Met+Cys & 0.58 & 0.40 \\
\hline Thr & 0.55 & 0.36 \\
\hline Trp & 0.30 & 0.26 \\
\hline Val & 1.00 & 0.79 \\
\hline Ile & 0.66 & 0.56 \\
\hline Leu & - & - \\
\hline His & - & - \\
\hline EW & 0.14 & 0.08 \\
\hline
\end{tabular}

The increase in the EAA levels in the adjusted diets was realized by supplementing L-Lys, DL-Met, LThr, L-Trp, L-Val and L-Ile to the control diets. The increase in dietary energy level (EW from 1.15 to 1.29 and from 1.15 to 1.23 in the weaner and starter diets, respectively) was realized by increasing the level of soy bean oil and rapeseed oil. The ingredient and calculated nutrient composition of the weaner and starter diets is shown in Appendix 2.

\subsection{Hygiene protocol}

In the daily routine procedures (e.g. feeding and checking clinical health) and in performing specific measurements (e.g. weighing), first the compartments with HSC pigs were considered before performing the same activities in LSC compartments. Before entering a HSC room, the following hygiene protocol was used by the personnel involved:

- Hands were washed or gloves were put on, a clean disposable overall, clean boots and gloves were put on and a hairnet was used. When entering a pen, plastic overshoes were put on and changed per pen or the boots were disinfected.

- In case of intensive animal contact (e.g. during weighing and veterinary treatment), the disposable overall and gloves were changed between each pen. In addition, plastic overshoes were changed or the boots were disinfected per pen.

- Per pen clean materials (e.g. weighing scale, needles) were used. At weighing of the piglets, an empty feed bag or crate was put in the weighing scale (to keep the weighing scale clean). The same empty feed bag or crate was used for all pigs in a pen and changed by a clean one for every pen. 


\subsection{Measurements}

\section{Body weight and feed intake}

The piglets were weighed individually at weaning and at day 9 and 35 after weaning. In addition, in case of culling, the culled piglet was weighed. Total feed intake per pen (feed supply - remainder of feed) was measured at every weighing of the piglets and in case of culling of a piglet. At every weighing of piglets, the remainders of the diet per pen were collected and weighed to determine the feed intake per pen.

\section{Culling, veterinary treatments and faecal scores}

The number of culled piglets and the number of piglets treated with antibiotics or other veterinary treatment were recorded including date and reason of culling and veterinary treatment. Feed intake and body weight of the culled piglet were registered on the day of culling to correct for the estimated feed intake of the culled animal. Faecal consistency scores were performed three times a week in the first three weeks after weaning. On Farm A, in each pen the number of piglets with normal faeces ( score $=1$ ), soft faeces (score = 2) and watery faeces (score $=3$ ) was scored visually by the same person across the treatment groups. On Farm B, the faeces of the pigs was scored on pen level with normal faeces (score $=0$ ), soft faeces (score $=1$ ), watery faeces (score $=2$ ) and extreme watery faeces (score $=3$ ) by the same person.

The wellbeing of the piglets was scored daily the first five days after weaning in the LSC piglets on Farm A and both the LSC and HSC piglets on Farm B. Per pen, the percentage of piglets with dirty eyes, tail wounds and ear wounds was scored. Morover, the percentage of piglets within a pen that was wheezing, sneezing, coughing, shivering and huddling was scored and the percentage of piglets in a pen that was active.

\section{Diets}

The weaner and starter diets were produced in one batch. Before the diets were delivered to the farms, they were analysed on the contents of crude protein with Near-Infrared Spectroscopy (NIR). When the absolute difference between calculated and analysed crude protein content was greater than $6 \mathrm{~g} / \mathrm{kg}$, the diet was produced again. The diets were analysed on dry matter, ash, crude protein, crude fat, crude fibre, starch, sugar and AA composition. Besides, the pellet hardness and durability of the diets were measured. Dry matter was analysed by drying at $103{ }^{\circ} \mathrm{C}$ (ISO 6496), ash by combustion to a constant weight at $550{ }^{\circ} \mathrm{C}$ (ISO, 5984), $\mathrm{N}$ by using the Dumas method (ISO 16634-1) and crude fat after hydrolysis (ISO, 6492). Starch was enzymatically determined (ISO 15914). Determination of sugars was based on the method described by Van Vuuren et al. (1993). Amino acid composition was analysed by acid hydrolysis at $110^{\circ} \mathrm{C}$ for $23 \mathrm{~h}$ and ion-exchange chromatography with post column derivatisation with ninhydrin (ISO13903; ISO, 2005a) and tryptophan by alkaline hydrolysis at $110^{\circ} \mathrm{C}$ for $20 \mathrm{~h}$ ion-exchange chromatography with fluorescence detection (MOD.0094 version G; ISO 13904; ISO, 2005c). Pellet durability was tested with durability testing equipment of Wemo Techniek. Pellet hardness was measured with a Dr Schleuniger hardness tester. The analysed nutrient composition of the diets is presentend in Appendix 3.

\section{Blood sampling}

For the purpose of regular health monitoring, on Farm B 32 (16 HSC piglets and 16 LSC piglets) of the 768 piglets in the trial were selected for blood sampling in week 3 (16 piglets in batch 1) or week 5 (16 piglets in batch 2) after weaning from the vena jugularis by the farm veterinarian. Four male piglets per dietary treatment per sanitary status were sampled. The blood samples were analysed on the acute phase protein haptoglobin (Animal Health Service, The Netherlands) and on antibodies against Actinobacillus pleuropneumoniae (APP), Mycoplasma hyopneumonia, PCV2 (Circovirus IgM and IgG), PPRS, Lawsonia intracellularis (PIA), Influenza A, Salmonella and Haemophilus parasuis (Glässer) (Veterinair Gelders Lab, The Netherlands). No blood samples for monitoring of health status were taken on Farm A.

\section{Room temperature}

In all rooms, the room temperature was monitored automatically every hour (see Appendix 4). Besides, on Farm $B$ the relative air humidity and level of $\mathrm{CO}_{2}$ were monitored every hour (see Appendix 4). 


\subsection{Statistical analysis}

The data were statistically analysed by means of F-tests using ANOVA (GenStat, 2018) using pen as the experimental unit. Results were considered as significant at $P \leq 0.05$ and as a trend at $P \leq 0.10$.

The performance data (average daily gain, average daily feed and energy intake, feed conversion ratio and energy conversion ratio) were analysed with a split-plot model. Sanitary condition was analysed on room level, sex on block level and dietary treatment on pen level.

$Y=\mu+$ batch + room within batch + sanitary condition + block within batch + sex + dietary treatment + sanitary condition $x$ sex + sanitary condition $x$ dietary treatment + sex $x$ dietary treatment + sanitary condition $x$ sex $x$ dietary treatment + residual error

There were no significant sanitary condition $x$ sex and sex $x$ dietary treatment interactions. Therefore, the $\mathrm{P}$-values for these interactions are not shown in the Tables.

The number of culled and veterinary treated piglets was analysed using the Chi-square test.

The percentage of piglets within a pen with soft or watery faeces (score 2 and 3) (Farm A) and the mean faecal score on pig level (Farm A) or pen level (Farm B) were analysed with the same model as used for the performance data. 


\section{Results}

\section{$3.1 \quad$ Diets}

The analysed nutrient composition (dry matter, ash, crude protein, crude fat, crude fibre, starch and sugar) of the diets and the analysed content of AA in the diets are presented in Appendix 3. Moreover, the pellet hardness and durability of the diets are presented in Appendix 3.

In the weaner diets, the analysed contents of dry matter, ash, crude protein, crude fat, crude fibre and sugar were as expected. The analysed starch content in the weaner diet with increased energy level was $29 \mathrm{~g} / \mathrm{kg}$ lower than the calculated starch content, whereas in the other three weaner diets the starch content was as expected. In the starter diets, the analysed contents of dry matter, ash, crude protein, crude fat and crude fibre were as expected. The analysed sugar contents were 8 to 11 $\mathrm{g} / \mathrm{kg}$ higher than the calculated values. The analysed starch content in the starter diet with increased energy level was $23 \mathrm{~g} / \mathrm{kg}$ lower than the calculated starch content, whereas in the other three starter diets the starch content was as expected.

In the weaner diets with increased energy and with increased AA + energy levels, the analysed lysine contents were 1.06 and $0.32 \mathrm{~g} / \mathrm{kg}$, respectively, higher than the calculated contents. In the weaner diet with increased energy level, the analysed contents of threonine, isoleucine and valine were 0.36 , 0.58 and $0.46 \mathrm{~g} / \mathrm{kg}$, respectively, higher than the calculated contents. For the other EAA in the weaner diets, the analysed contents were as expected. In the starter diet with increased AA + energy levels, the analysed content of methionine was $0.31 \mathrm{~g} / \mathrm{kg}$ lower than the calculated content. The analysed content of threonine in the starter diet with increased energy level was $0.15 \mathrm{~g} / \mathrm{kg}$ higher than the calculated content whereas in the other three starter diets the analysed contents of threonine were 0.18 to $0.39 \mathrm{~g} / \mathrm{kg}$ lower than the calculated contents. For the other EAA in the starter diets, the analysed contents were as expected.

Pellet hardness and durability were lower in the weaner and starter diet with increased energy and increased $A A+$ energy levels than in the control diets and the diets with only increased AA levels.

\subsection{Performance}

The performance of the piglets from weaning till day 35 after weaning on Farm A is presented in Table 2 and Figure 1.

Table 2 and Figure 1 show that from weaning till day 35 after weaning, ADG, ADFI and average daily energy intake (ADEI) were not significantly affected by sanitary conditions. Feed conversion ratio (FCR) and energy conversion ratio (ECR) were lower in HSC piglets than in LSC piglets.

Average daily gain tended to be higher in LSC piglets fed the diets with increased AA or increased AA + energy levels than in LSC piglets fed the control diet. In HSC piglets, dietary treatment did not affect ADG. In LSC piglets, ADFI was not affected by dietary treatment, whereas ADEI was highest in piglets fed the diet with increased AA + energy levels. In HSC piglets, ADFI tended to be lower in piglets fed the diet with increased AA + energy levels than in piglets fed the control diet, whereas ADEI was not affected by dietary treatment. Feed conversion ratio was lower in piglets fed the diets with increased $A A$ or increased $A A+$ energy levels than in piglets fed the control diet. Energy conversion ratio was lowest in piglets fed the diet with increased $A A$ levels and highest in piglets fed the diet with increased AA + energy levels.

Average daily gain tended to be higher in gilts than in boars whereas ADFI, ADEI, FCR and ECR were significantly higher in gilts than in boars. 
Table 2 Performance from weaning (day 0) till day 35 after weaning of boars and gilts that were kept under different sanitary conditions (SC) and were fed diets differing in energy and essential amino acid content (Farm A).

\begin{tabular}{|c|c|c|c|c|c|c|c|c|c|c|c|c|c|}
\hline & $\operatorname{sc}^{1}$ & sc & \multicolumn{3}{|c|}{ Dietary treatment ${ }^{2}$} & SEM $^{3}$ & \multicolumn{2}{|c|}{ Sex } & SEM & \multicolumn{4}{|c|}{ P-value } \\
\hline $\begin{array}{l}\text { No of } \\
\text { piglets }\end{array}$ & HSC & 344 & 115 & 115 & 114 & & 179 & 165 & & & & & \\
\hline $\begin{array}{l}\text { No of } \\
\text { pens }\end{array}$ & LSC & 51 & 17 & 17 & 17 & & 27 & 24 & & & & & \\
\hline
\end{tabular}

\begin{tabular}{|c|c|c|c|c|c|c|c|c|c|c|c|c|c|}
\hline \multicolumn{14}{|c|}{$B W(k g):$} \\
\hline \multirow[t]{2}{*}{ Day 0} & LSC & 7.6 & 7.6 & 7.6 & 7.6 & 0.01 & 7.6 & 7.6 & 0.08 & 0.98 & 0.89 & 0.64 & 0.98 \\
\hline & HSC & 7.6 & 7.6 & 7.6 & 7.6 & & 7.6 & 7.6 & & & & & \\
\hline \multirow[t]{2}{*}{ Day 35} & LSC & 22.6 & $22.1^{x}$ & $22.9^{y}$ & $22.9^{y}$ & 0.18 & 22.4 & 22.9 & 0.14 & 0.94 & 0.12 & 0.10 & 0.11 \\
\hline & HSC & 22.6 & $22.6^{x y}$ & $22.8^{x y}$ & $22.3^{x y}$ & & 22.4 & 22.7 & & & & & \\
\hline
\end{tabular}

\begin{tabular}{|c|c|c|c|c|c|c|c|c|c|c|c|c|c|}
\hline \multicolumn{14}{|c|}{ Weaning till day 35: } \\
\hline \multirow{2}{*}{$\begin{array}{l}\text { ADG } \\
(g / d)\end{array}$} & LSC & 430 & $416^{x}$ & $438^{y}$ & $437^{y}$ & 5.0 & 424 & 436 & 3.2 & 0.91 & 0.12 & 0.09 & 0.11 \\
\hline & HSC & 428 & $429^{x y}$ & $436^{x y}$ & $420^{x y}$ & & 425 & 431 & & & & & \\
\hline \multirow{2}{*}{$\begin{array}{l}\text { ADFI } \\
(\mathrm{kg} / \mathrm{d})\end{array}$} & LSC & 0.59 & $0.58^{x y}$ & $0.59^{y}$ & $0.60^{y}$ & 0.006 & 0.57 & 0.60 & 0.005 & 0.36 & 0.17 & 0.003 & 0.06 \\
\hline & HSC & 0.57 & $0.59^{y}$ & $0.57^{x y}$ & $0.55^{x}$ & & 0.56 & 0.58 & & & & & \\
\hline \multirow{2}{*}{$\begin{array}{l}\mathrm{ADEI}^{5} \\
(\mathrm{EW} / \mathrm{d})\end{array}$} & LSC & 0.69 & $0.67^{a}$ & $0.68^{a}$ & $0.73^{b}$ & 0.007 & 0.68 & 0.71 & 0.006 & 0.36 & 0.002 & 0.003 & 0.05 \\
\hline & HSC & 0.67 & $0.67^{a}$ & $0.66^{a}$ & $0.68^{a}$ & & 0.65 & 0.68 & & & & & \\
\hline \multirow[t]{2}{*}{$\mathrm{ECR}^{6}$} & LSC & 1.61 & $1.62^{c}$ & $1.55^{b}$ & $1.67^{d}$ & 0.005 & 1.59 & 1.62 & 0.006 & 0.002 & $<0.001$ & $<0.001$ & 0.64 \\
\hline & HSC & 1.56 & $1.57^{b}$ & $1.50^{\mathrm{a}}$ & $1.61^{c}$ & & 1.54 & 1.58 & & & & & \\
\hline
\end{tabular}

${ }^{1} \mathrm{SC}=$ sanitary conditions; $\mathrm{LSC}=$ low sanitary conditions; $\mathrm{HSC}=$ high sanitary conditions; ${ }^{2}$ control = basal dietary energy and amino acid $(A A)$ content; $+A A=$ increased levels of SID AA; +AA+Energy = increased levels of SID AA and energy; ${ }^{3}$ $\mathrm{SEM}=$ pooled SEM. Means are presented as least squares means; ${ }^{4} \mathrm{D}=$ dietary treatment; ${ }^{5} \mathrm{ADEI}=$ average daily energy intake; ${ }^{6} \mathrm{ECR}=$ energy conversion ratio. Values with a different letter within dietary treatment, differ at a significance level of $\mathrm{p}<0.05$ (abcd) or $\mathrm{p}<0.10(\mathrm{xy})$.

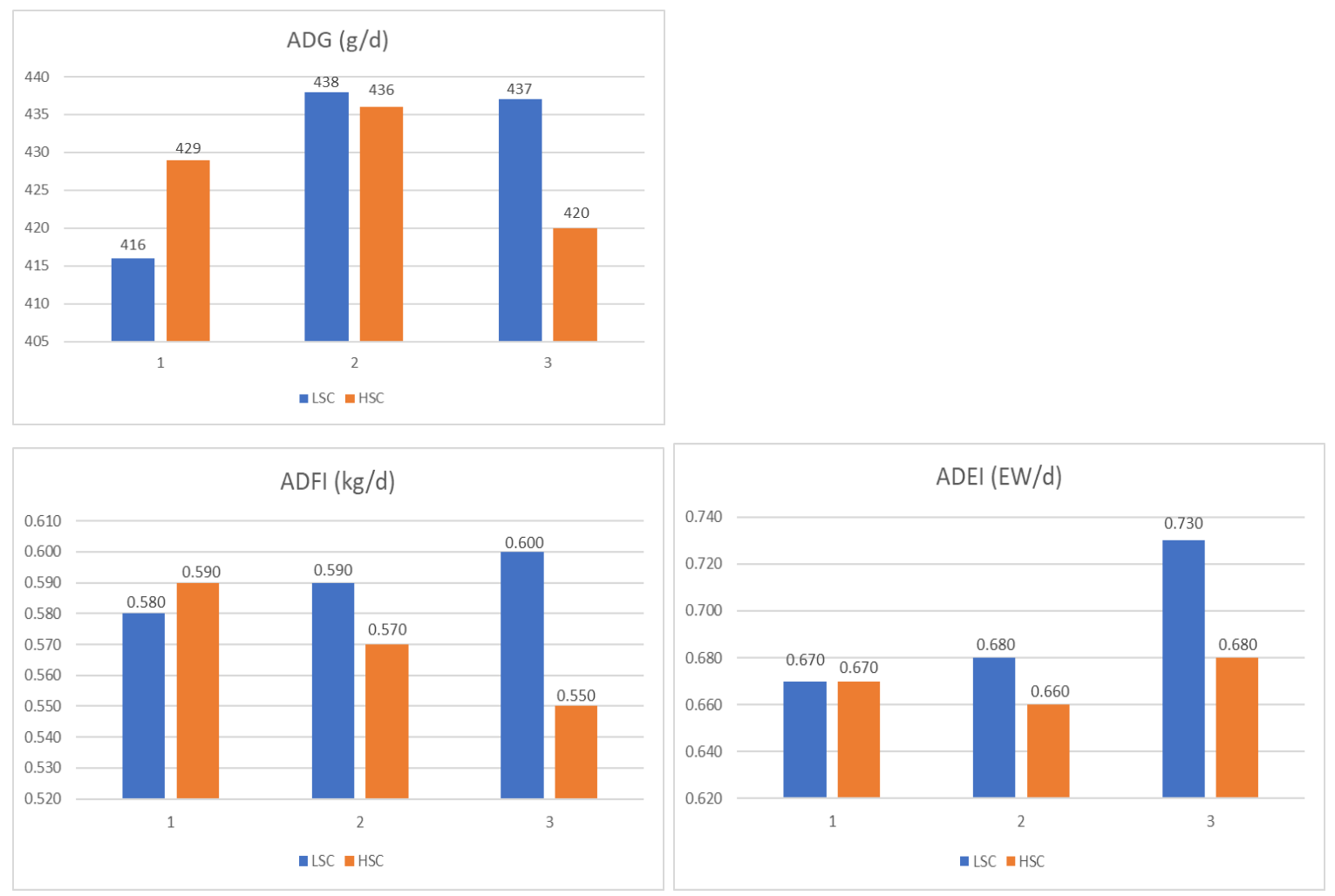




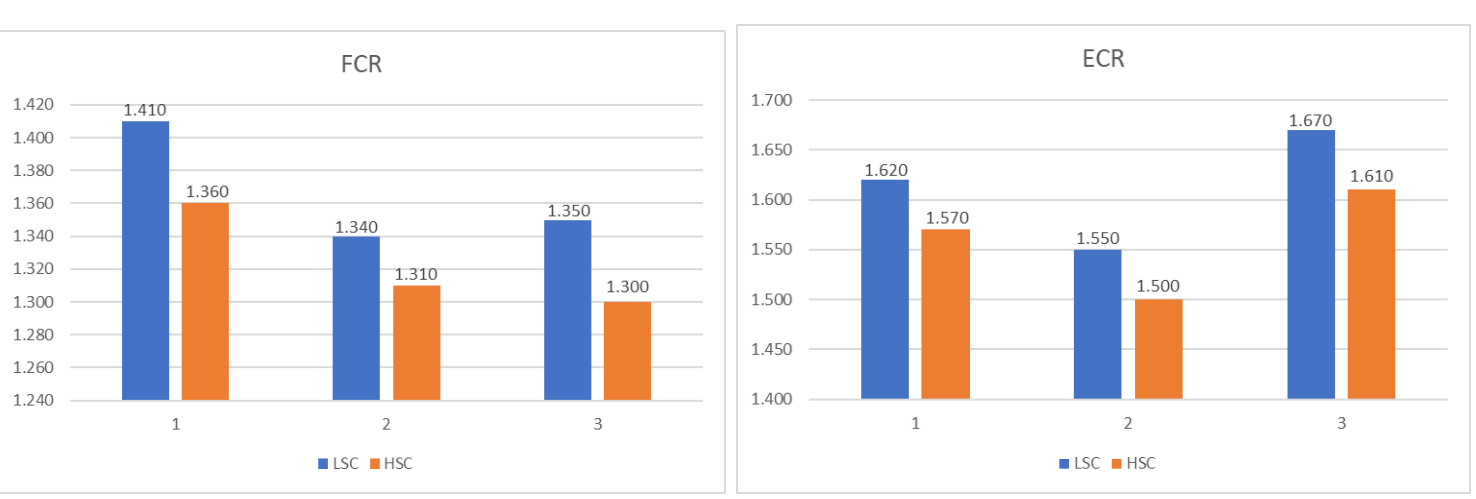

Figure 1 Average daily gain (ADG), average daily feed intake (ADFI), average daily energy intake $(A D E I)$, feed conversion ratio (FCR) and energy conversion ratio (ECR) from weaning (day 0) till day 35 after weaning of boars and gilts that were kept under high (HSC) or Iow (LSC) sanitary conditions and were fed diets differing in energy and essential amino acid content ( 1 = basal dietary energy and amino acid $(A A)$ content; 2 = increased levels of SID AA; 3 = increased levels of SID AA and energy) (Farm $A$ ).

The performance of the piglets from weaning till day 35 after weaning on Farm B is presented in Table 3 and Figure 2.

Table 3 Performance from weaning (day 0) till day 35 after weaning of boars and gilts that were kept under different sanitary conditions (SC) and were fed diets differing in energy and essential amino acid content (Farm B).

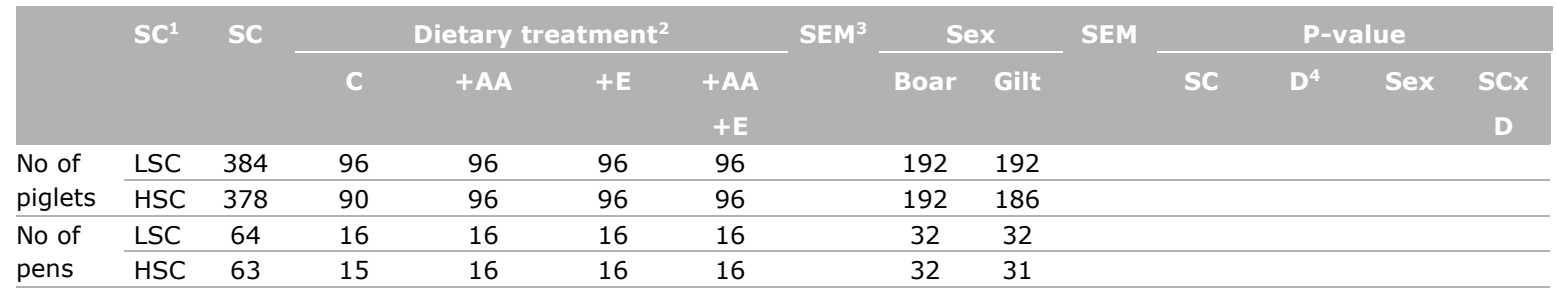

\begin{tabular}{|c|c|c|c|c|c|c|c|c|c|c|c|c|c|c|}
\hline \multicolumn{15}{|c|}{$B W(\mathrm{~kg}):$} \\
\hline \multirow[t]{2}{*}{ Day 0} & LSC & 8.2 & 8.2 & 8.1 & 8.3 & 8.1 & 0.06 & 8.2 & 8.1 & 0.31 & 0.97 & 0.18 & 0.71 & 0.33 \\
\hline & HSC & 8.2 & 8.0 & 8.1 & 8.3 & 8.3 & & 8.3 & 8.1 & & & & & \\
\hline \multirow[t]{2}{*}{ Day 35} & LSC & 24.8 & $25.0^{\mathrm{ab}}$ & $25.7^{b}$ & $24.1^{a}$ & $24.4^{a}$ & 0.30 & 24.9 & 24.7 & 0.62 & 0.23 & 0.03 & 0.92 & 0.82 \\
\hline & HSC & 26.2 & $26.2^{b c}$ & $26.8^{c}$ & $25.9^{\mathrm{b}}$ & $26.0^{\mathrm{b}}$ & & 26.0 & 26.4 & & & & & \\
\hline
\end{tabular}

\begin{tabular}{|c|c|c|c|c|c|c|c|c|c|c|c|c|c|c|}
\hline \multicolumn{15}{|c|}{ Weaning till day 35: } \\
\hline \multirow{2}{*}{$\begin{array}{l}A D G \\
(g / d)\end{array}$} & LSC & 475 & $480^{\mathrm{ab}}$ & $502^{\mathrm{bc}}$ & $453^{a}$ & $467^{a}$ & 7.5 & 477 & 474 & 10.0 & 0.27 & 0.002 & 0.62 & 0.86 \\
\hline & HSC & 516 & $518^{\mathrm{cd}}$ & $535^{d}$ & $504^{\mathrm{bc}}$ & $506^{\mathrm{bc}}$ & & 507 & 524 & & & & & \\
\hline \multirow{2}{*}{$\begin{array}{l}\text { ADFI } \\
(\mathrm{kg} / \mathrm{d})\end{array}$} & LSC & 0.69 & $0.71^{\mathrm{b}}$ & $0.72^{b c}$ & $0.67^{a}$ & $0.67^{a}$ & 0.011 & 0.69 & 0.70 & 0.013 & 0.34 & 0.007 & 0.17 & 0.78 \\
\hline & HSC & 0.71 & $0.72^{\mathrm{bc}}$ & $0.73^{c}$ & $0.71^{\mathrm{b}}$ & $0.69^{\mathrm{ab}}$ & & 0.70 & 0.73 & & & & & \\
\hline \multirow{2}{*}{$\begin{array}{l}\mathrm{ADEI}^{5} \\
(\mathrm{EW} / \mathrm{d})\end{array}$} & LSC & 0.83 & 0.82 & 0.83 & 0.83 & 0.83 & 0.013 & 0.82 & 0.84 & 0.016 & 0.35 & 0.44 & 0.18 & 0.76 \\
\hline & HSC & 0.85 & 0.83 & 0.84 & 0.88 & 0.85 & & 0.83 & 0.87 & & & & & \\
\hline \multirow[t]{2}{*}{$\mathrm{ECR}^{6}$} & LSC & 1.75 & $1.71^{\mathrm{cd}}$ & $1.65^{\mathrm{ab}}$ & $1.84^{f}$ & $1.78^{\mathrm{e}}$ & 0.016 & 1.72 & 1.78 & 0.010 & 0.23 & $<0.001$ & 0.007 & 0.89 \\
\hline & HSC & 1.65 & $1.61^{\mathrm{a}}$ & $1.57^{\mathrm{a}}$ & $1.74^{\mathrm{de}}$ & $1.68^{\mathrm{bc}}$ & & 1.63 & 1.66 & & & & & \\
\hline
\end{tabular}

${ }^{1} \mathrm{SC}=$ sanitary conditions; LSC = low sanitary conditions; HSC $=$ high sanitary conditions; ${ }^{2} \mathrm{C}=$ control = basal dietary energy and amino acid $(A A)$ content; $+A A=$ increased levels of SID $A A ;+E=$ increased level of energy; $+A A+E=$ increased levels of SID AA and energy; ${ }^{3}$ SEM = pooled SEM. Means are presented as least squares means; ${ }^{4} \mathrm{D}=$ dietary treatment; ${ }^{5}$ $\mathrm{ADEI}=$ average daily energy intake; ${ }^{6} \mathrm{ECR}=$ energy conversion ratio. Values with a different letter within dietary treatment, differ at a significance level of $p<0.05$ (abcdef).

Table 3 and Figure 2 show that from weaning till day 35 after weaning, performance of the piglets was not significantly affected by sanitary conditions.

Average daily gain and ADFI were higher in piglets fed the diet with increased AA levels than in piglets fed the diets with increased energy or increased AA + energy levels whereas ADG and ADFI of the piglets on the control diet was in between. Average daily energy intake was not affected by dietary treatment. Feed conversion ratio was lower in piglets fed the diets with increased AA or increased AA 
+ energy levels than in piglets fed the control diet or the diet with increased energy level. Energy conversion ratio was lowest in piglets fed the diet with increased AA levels and highest in piglets fed the diet with increased energy level.

Average daily gain, ADFI and ADEI did not differ between boars and gilts whereas FCR and ECR were higher in gilts than in boars.
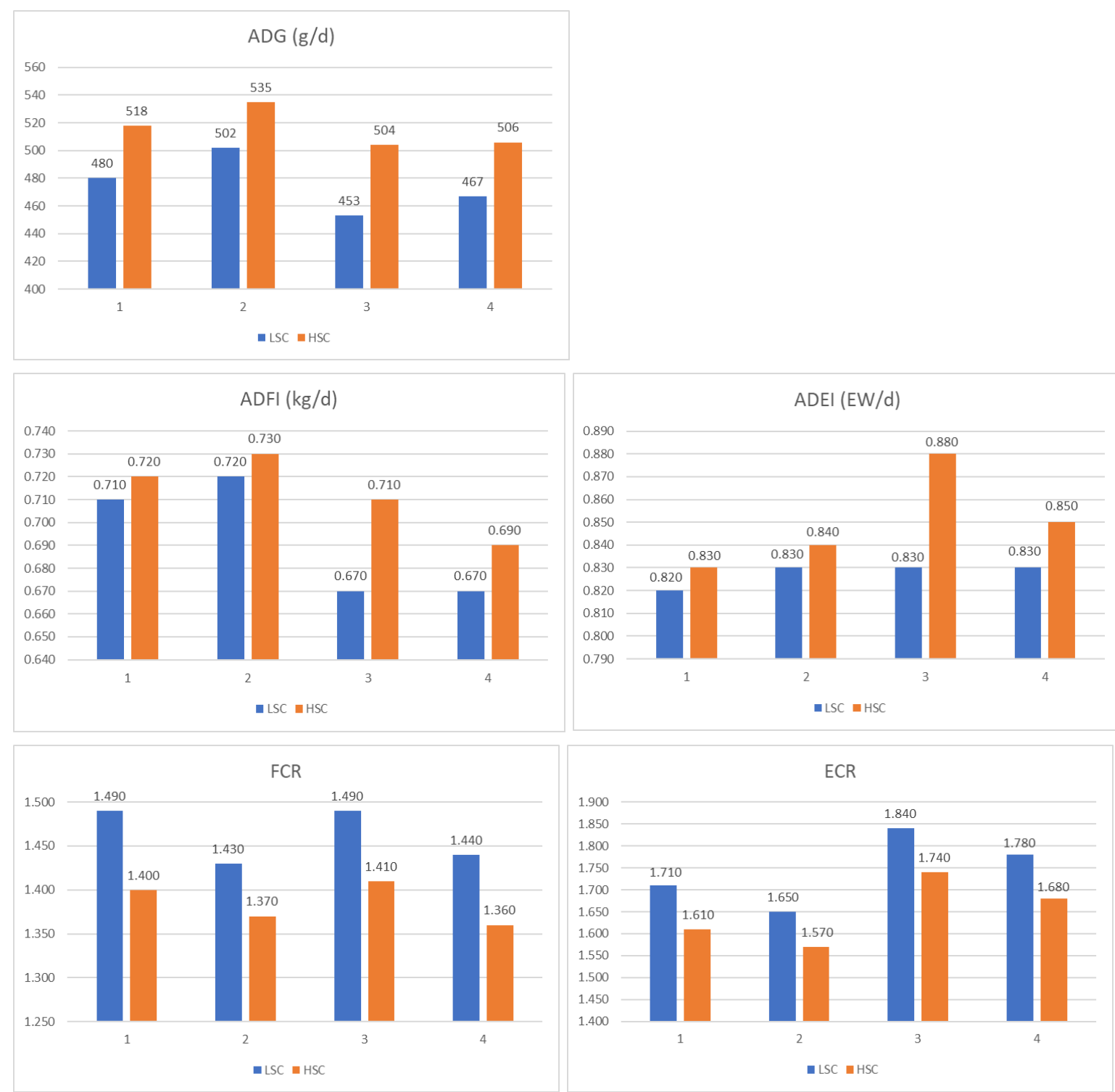

Figure 2 Average daily gain (ADG), average daily feed intake (ADFI), average daily energy intake $(A D E I)$, feed conversion ratio (FCR) and energy conversion ratio (ECR) from weaning (day 0) till day 35 after weaning of boars and gilts that were kept under high (HSC) or Iow (LSC) sanitary conditions and were fed diets differing in energy and essential amino acid content ( 1 = basal dietary energy and amino acid $(A A)$ content; 2 = increased levels of SID AA; 3 = increased level of energy; 4 = increased levels of SID AA and energy) (Farm B).

The performance of the piglets from weaning till day 9 after weaning and from day 9 till day 35 after weaning on Farm $A$ is presented in Table 4. 
Performance from weaning (day 0) till day 9 after weaning and from day 9 till day 35 after weaning of boars and gilts that were kept under different sanitary conditions (SC) and were fed diets differing in energy and essential amino acid content (Farm A).

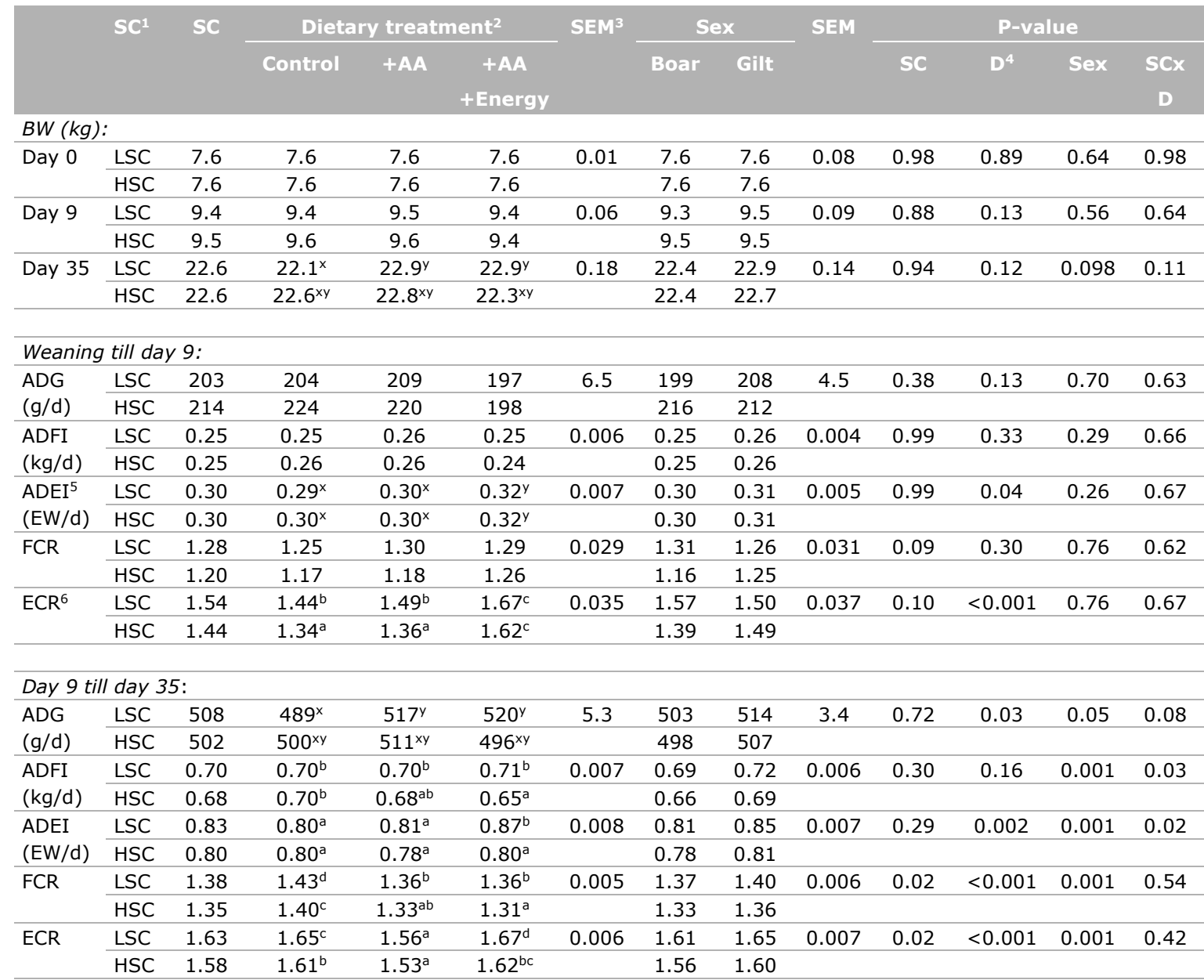

${ }^{1} \mathrm{SC}=$ sanitary conditions; LSC = low sanitary conditions; HSC = high sanitary conditions; ${ }^{2}$ control = basal dietary energy and amino acid (AA) content; +AA = increased levels of SID AA; +AA+Energy = increased levels of SID AA and energy; ${ }^{3}$ $\mathrm{SEM}=$ pooled SEM. Means are presented as least squares means; ${ }^{4} \mathrm{D}=$ dietary treatment; ${ }^{5} \mathrm{ADEI}=$ average daily energy intake; ${ }^{6} \mathrm{ECR}=$ energy conversion ratio. Values with a different letter within dietary treatment, differ at a significance level of $\mathrm{p}<0.05$ (abcd) or $\mathrm{p}<0.10(\mathrm{xy})$.

Table 4 shows that from weaning till day 9 after weaning, ADG, ADFI and ADEI were not significantly affected by sanitary conditions. Feed conversion ratio and energy ECR tended to be lower in HSC piglets than in LSC piglets. Average daily gain, ADFI and FCR were not affected by dietary treatment whereas $A D E I$ and ECR ratio were higher in piglets fed the diet with increased $A A+$ energy levels than in piglets fed the control diet or the diet with increased AA levels. Performance did not differ between boars and gilts.

From day 9-35 after weaning, ADG, ADFI and ADEI were not significantly affected by sanitary conditions. Feed conversion ratio and energy ECR were lower in HSC piglets than in LSC piglets. Average daily gain tended to be higher in LSC piglets fed the diets with increased AA or increased AA + energy levels than in LSC piglets fed the control diet. In HSC piglets, dietary treatment did not affect ADG. In LSC piglets, ADFI was not affected by dietary treatment, whereas ADEI was highest in piglets fed the diet with increased AA + energy levels. In HSC piglets, ADFI was lower in piglets fed the diet with increased $A A+$ energy levels than in piglets fed the control diet, whereas ADEI was not affected by dietary treatment. Feed conversion ratio was lower in piglets fed the diets with increased $A A$ or increased $A A+$ energy levels than in piglets fed the control diet. Energy conversion ratio was lowest in piglets fed the diet with increased $A A$ levels and highest in piglets fed the diet with increased $A A+$ energy levels. Average daily gain, ADFI, ADEI, FCR and ECR were significantly higher in gilts than in boars. 
The performance of the piglets from weaning till day 9 after weaning and from day 9 till day 35 after weaning on Farm B is presented in Table 5.

Table $5 \quad$ Performance from weaning (day 0) till day 9 after weaning and from day 9 till day 35 after weaning of boars and gilts that were kept under different sanitary conditions (SC) and were fed diets differing in energy and essential amino acid content (Farm $B$ ).

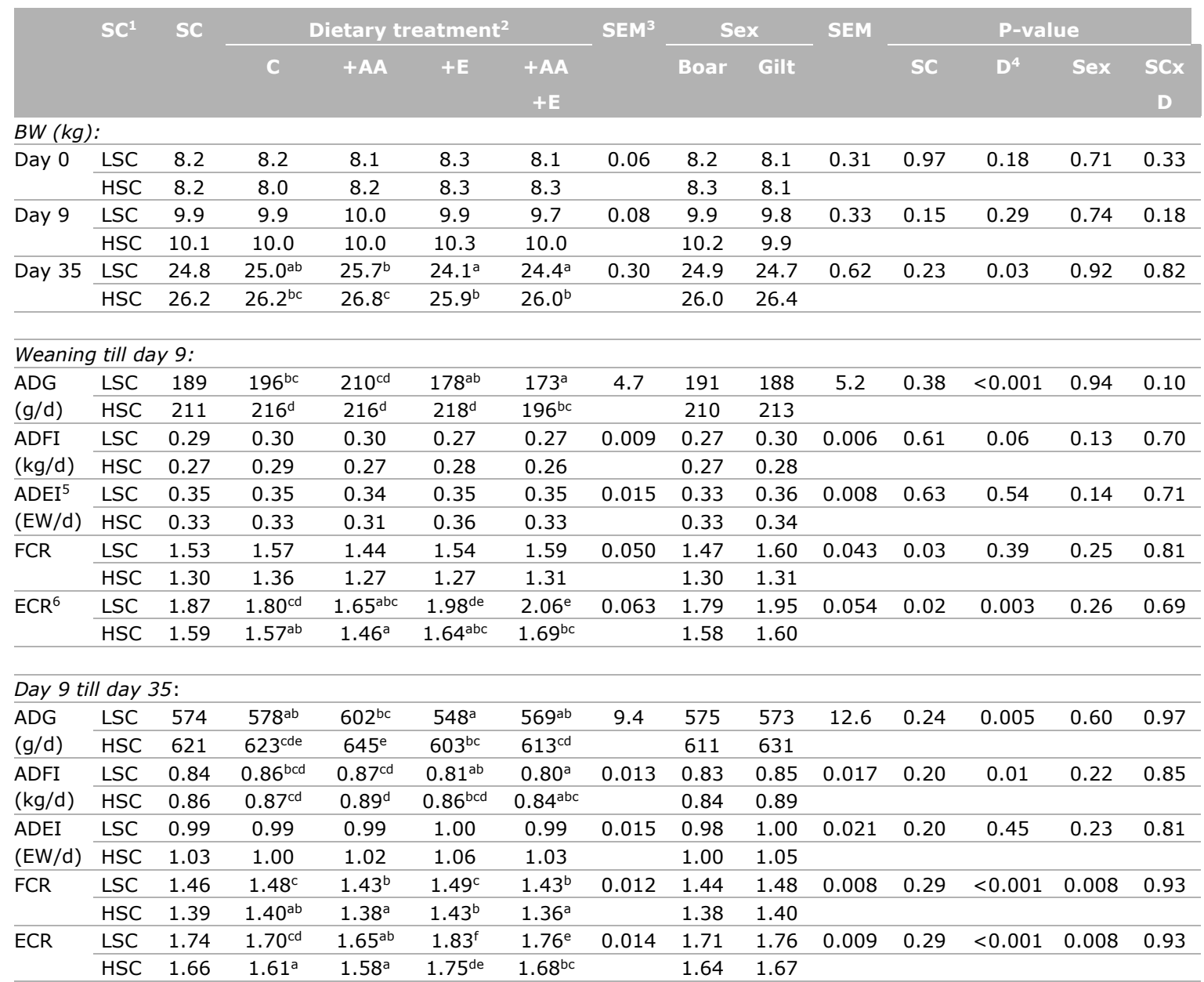

${ }^{1} \mathrm{SC}=$ sanitary conditions; LSC = low sanitary conditions; HSC = high sanitary conditions; ${ }^{2} \mathrm{C}=$ control $=$ basal dietary energy and amino acid $(A A)$ content; $+A A=$ increased levels of SID $A A ;+E=$ increased level of energy; $+A A+E=$ increased levels of SID AA and energy; ${ }^{3}$ SEM = pooled SEM. Means are presented as least squares means; ${ }^{4} \mathrm{D}=$ dietary treatment; ${ }^{5}$ ADEI = average daily energy intake; ${ }^{6} \mathrm{ECR}=$ energy conversion ratio. Values with a different letter within dietary treatment, differ at a significance level of $p<0.05$ (abcdef).

Table 5 shows that from weaning till day 9 after weaning, ADG, ADFI and ADEI were not significantly affected by sanitary conditions. Feed conversion ratio and energy ECR were lower in HSC piglets than in LSC piglets. In LSC piglets, ADG was higher in piglets fed the diet with increased AA levels than in piglets fed the diets with increased energy or increased AA + energy levels, whereas ADG of the piglets on the control diet was in between. In HSC piglets, ADG was lower in piglets fed the diet with increased $A A+$ energy level, whereas ADG was similar in the other three dietary treatments. Average daily feed intake was lower in piglets fed the diet with increased $A A+$ energy level than in piglets fed the control diet, whereas ADFI of the piglets fed the diets with increased AA or energy levels were in between. Average daily energy intake was not affected by dietary treatment. Moreover, FCR was not affected by dietary treatment. Energy conversion ratio was lowest in piglets fed the diet with increased AA levels and highest in piglets fed the diets with increased energy or increased AA + energy level. Performance did not differ between boars and gilts.

From day 9-35 after weaning, performance of the piglets was not significantly affected by sanitary conditions. Average daily gain and ADFI were higher in piglets fed the diet with increased AA levels than in piglets fed the diets with increased energy or increased AA + energy levels whereas ADG and ADFI of the piglets on the control diet was in between. Average daily energy intake was not affected 
by dietary treatment. Feed conversion ratio was lower in piglets fed the diets with increased AA or increased $A A+$ energy levels than in piglets fed the control diet or the diet with increased energy level. Energy conversion ratio was lowest in piglets fed the diet with increased $A A$ levels and highest in piglets fed the diet with increased energy level. Average daily gain, ADFI and ADEI did not differ between boars and gilts whereas FCR and ECR were higher in gilts than in boars.

The standard deviation (SD) in BW of the weaned piglets within a pen at weaning and day 9 and 35 after weaning on Farm A are presented in Table 6.

Table 6 Standard deviation (SD; kg) in BW within a pen at weaning (day 0) and day 9 and 35 after weaning of boars and gilts that were kept under different sanitary conditions (SC) and were fed diets differing in energy and essential amino acid content (Farm A).

\begin{tabular}{|c|c|c|c|c|c|c|c|c|c|c|c|c|c|}
\hline & \multirow[t]{2}{*}{$\mathrm{SC}^{1}$} & \multirow[t]{2}{*}{ sc } & \multicolumn{3}{|c|}{ Dietary treatment ${ }^{2}$} & \multirow[t]{2}{*}{$S E M^{3}$} & \multicolumn{2}{|c|}{ Sex } & \multirow[t]{2}{*}{ SEM } & \multicolumn{4}{|c|}{ P-value } \\
\hline & & & & & +Energy & & & & & & & & \\
\hline $\begin{array}{l}\text { SD BW } \\
\text { day } 0\end{array}$ & HSC & 0.58 & 0.58 & 0.57 & 0.57 & & 0.61 & 0.54 & & & & & \\
\hline $\begin{array}{l}\text { SD BW } \\
\text { day } 9\end{array}$ & LSC & 1.02 & 1.04 & 0.98 & 1.04 & 0.047 & 1.01 & 1.02 & 0.052 & 0.57 & 0.80 & 0.96 & 0.93 \\
\hline $\begin{array}{l}\text { SD BW } \\
\text { day } 35\end{array}$ & HSC & 2.89 & 2.77 & 3.11 & 2.80 & & 2.62 & 3.16 & & & & & \\
\hline
\end{tabular}

${ }^{1} \mathrm{SC}=$ sanitary conditions; LSC = low sanitary conditions; HSC = high sanitary conditions; ${ }^{2}$ control = basal dietary energy and amino acid (AA) content; +AA = increased levels of SID AA; +AA+Energy = increased levels of SID AA and energy; ${ }^{3}$ $\mathrm{SEM}=$ pooled SEM. Means are presented as least squares means; ${ }^{4} \mathrm{D}=$ dietary treatment.

Table 6 shows that SD in BW was not affected by sanitairy conditions and by dietary treatment. Moreover, SD in BW was not affected by sex at the day of weaning and day 9 after weaning. At day 35 after weaning, SD in BW was higher in gilts than in boars. The SD in BW increased from weaning till day 35 after weaning.

The standard deviation (SD) in BW of the weaned piglets within a pen at weaning and day 9 and 35 after weaning on Farm B are presented in Table 7.

Table $7 \quad$ Standard deviation (SD; kg) in BW within a pen at weaning (day 0) and day 9 and 35 after weaning of boars and gilts that were kept under different sanitary conditions (SC) and were fed diets differing in energy and essential amino acid content (Farm B).

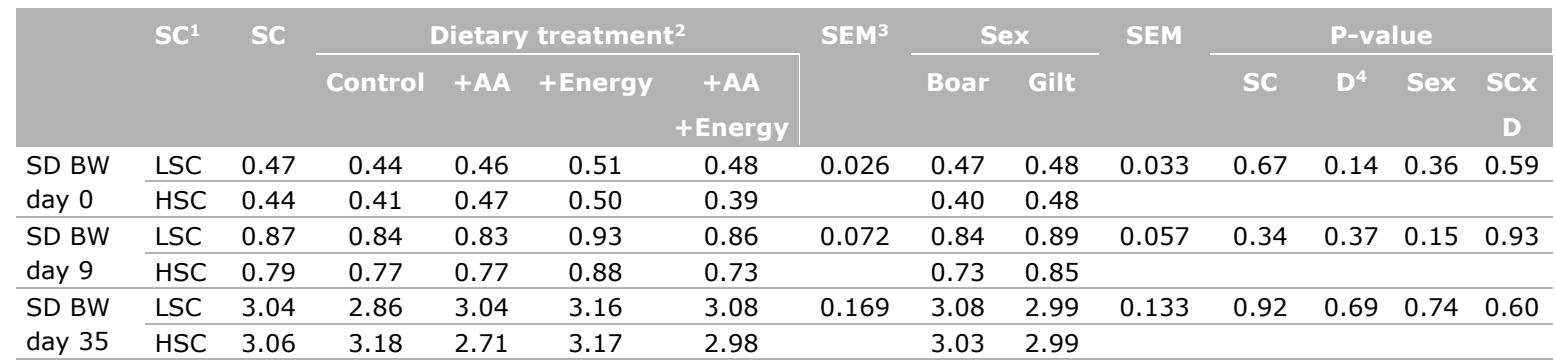

${ }^{1} \mathrm{SC}=$ sanitary conditions; LSC $=$ low sanitary conditions; HSC $=$ high sanitary conditions; ${ }^{2}$ control = basal dietary energy and amino acid $(A A)$ content; +AA = increased levels of SID AA; +Energy = increased level of energy; +AA+Energy = increased levels of SID AA and energy; ${ }^{3}$ SEM = pooled SEM. Means are presented as least squares means; ${ }^{4} \mathrm{D}=$ dietary treatment.

Table 7 shows that SD in BW was not affected by sanitairy conditions, dietary treatment and sex. The SD in BW increased from weaning till day 35 after weaning.

\subsection{Health and faecal scores}

The number of culled and veterinary treated weaned piglets on Farm A is presented in Table 8. Also the reasons of culling and veterinary treatment are presented. 
Table $8 \quad$ Number of culled and veterinary treated weaned piglets (boars and gilts) that were kept under different sanitary conditions (SC) and were fed diets differing in energy and essential amino acid content (Farm A).

\begin{tabular}{|c|c|c|c|c|c|c|c|c|c|}
\hline & \multicolumn{3}{|c|}{$\mathrm{LSC}^{1}$} & \multicolumn{3}{|c|}{$\mathrm{HSC}^{1}$} & \multicolumn{3}{|c|}{ P-value } \\
\hline No of pigs & 115 & 115 & 115 & 115 & 115 & 114 & & & \\
\hline \multicolumn{10}{|l|}{ Reason of culling: } \\
\hline - infection with S. suis & 0 & 0 & 0 & 0 & 1 & 1 & 4 & 4 & 4 \\
\hline - leg problems & 0 & 0 & 0 & 0 & 1 & 0 & 4 & 4 & 4 \\
\hline - poor growth & 0 & 1 & 1 & 0 & 1 & 0 & 4 & 4 & 4 \\
\hline - dead (reason unknown) & 0 & 1 & 0 & 0 & 0 & 0 & 4 & 4 & 4 \\
\hline - miscellaneous & 2 & 0 & 0 & 1 & 0 & 0 & 4 & 4 & 4 \\
\hline No of veterinary treated pigs ${ }^{6}$ & 12 & 5 & 6 & 5 & 4 & 8 & 0.33 & 0.27 & 0.78 \\
\hline
\end{tabular}

${ }^{1}$ LSC = low sanitary conditions; HSC = high sanitary conditions; ${ }^{2}$ control = basal dietary energy and amino acid (AA) content; $+\mathrm{AA}=$ increased levels of SID AA; +AA+Energy = increased levels of SID AA and energy; ${ }^{3} \mathrm{D}=$ dietary treatment; ${ }^{4}$ Numbers too low to allow statistical analysis; ${ }^{5}$ LSC: 3 boars and 1 gilt were culled; HSC: 3 boars and 3 gilts were culled; ${ }^{6}$ LSC: 14 boars and 9 gilts were veterinary treated; HSC: 6 boars and 11 gilts were veterinary treated.

Table 8 shows that sanitary conditions, dietary treatment and sex did not affect the number of culled and of veterinary treated piglets.

The number of culled and veterinary treated weaned piglets on Farm B is presented in Table 9. Also the reasons of culling and veterinary treatment are presented.

Table $9 \quad$ Number of culled and veterinary treated weaned piglets (boars and gilts) that were kept under different sanitary conditions (SC) and were fed diets differing in energy and essential amino acid content (Farm B).

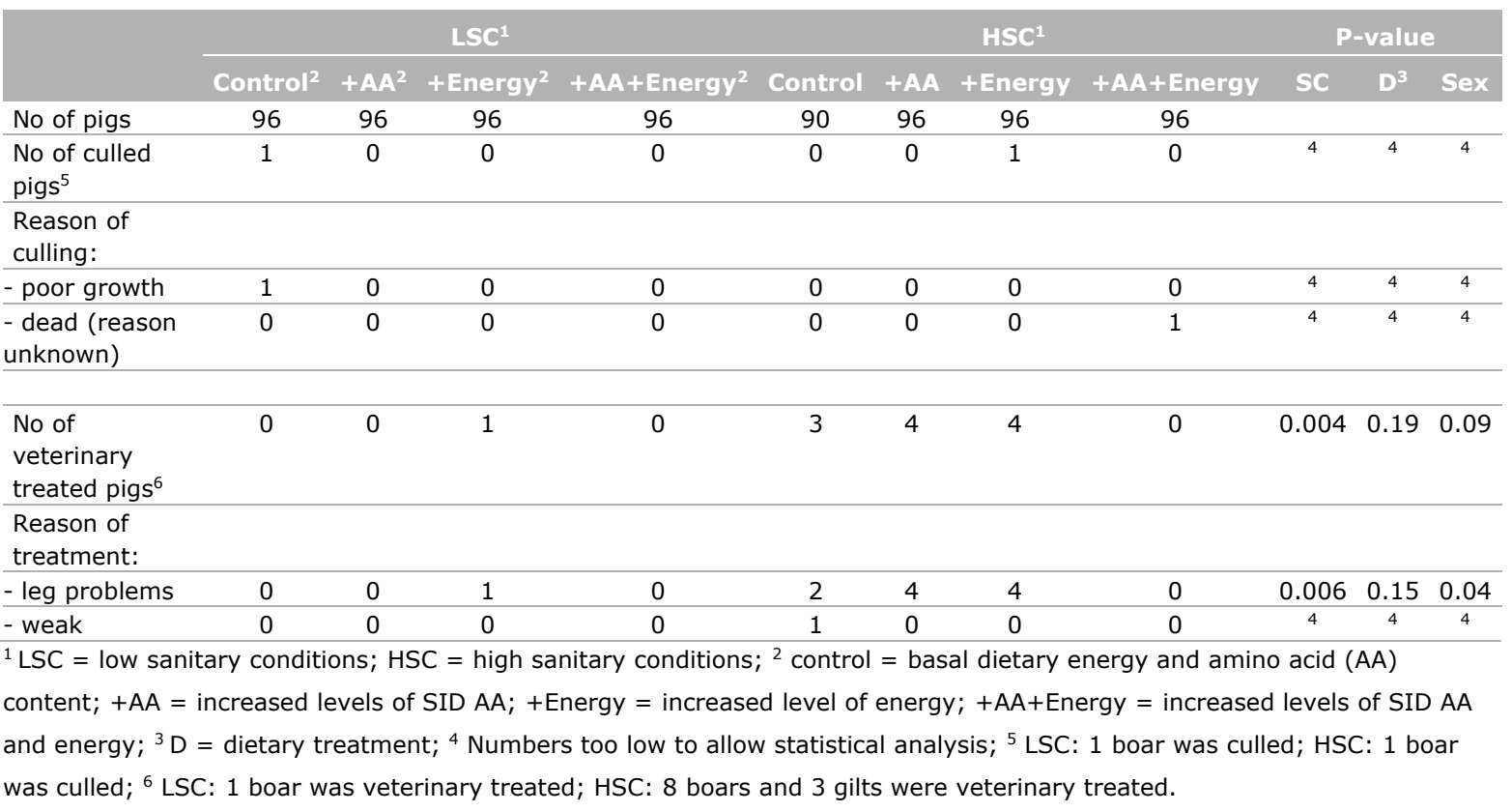

Table 9 shows that sanitary conditions, dietary treatment and sex did not affect the number of culled piglets. The number of veterinary treated piglets was higher in HSC piglets than in LSC piglets and higher in boars than in gilts. Especially, the number of piglets that was treated due to leg problems was higher in HSC piglets and in boars. Dietary treatment did not affect the number of culled and of veterinary treated piglets. 
The percentage of weaned piglets with diarrhoea (score 2 and 3) within a pen in week 1, 2 and 3 after weaning on Farm $A$ is presented in Table 10. On Farm A, in each pen the number of piglets with normal faeces (score $=1$ ), soft faeces (score $=2$ ) and watery faeces (score $=3$ ) was scored visually by the same person.

Table 10 Percentage of weaned piglets with soft or watery faeces (score 2 and 3) ${ }^{1}$ within a pen that were kept under different sanitary conditions (SC) and were fed diets differing in energy and essential amino acid content (Farm A).

\begin{tabular}{|c|c|c|c|c|c|c|c|c|c|c|c|}
\hline Week & $\mathrm{Sc}^{2}$ & SC & \multicolumn{3}{|c|}{ Dietary treatment ${ }^{3}$} & \multicolumn{2}{|c|}{ Sex } & \multicolumn{4}{|c|}{ P-value } \\
\hline 1 & LSC & 39.8 & $39.4^{\mathrm{bc}}$ & $34.2^{\mathrm{b}}$ & $45.7^{c}$ & 40.6 & 38.9 & 0.005 & 0.67 & 0.97 & 0.03 \\
\hline \multirow[t]{2}{*}{2} & LSC & 49.8 & $48.6^{x y}$ & $46.9^{w x}$ & $53.7^{y z}$ & 52.2 & 47.4 & 0.15 & 0.25 & 0.13 & 0.11 \\
\hline & HSC & 43.8 & $45.2^{w x}$ & $43.2^{w}$ & $42.9^{w}$ & 44.3 & 43.2 & & & & \\
\hline 3 & LSC & 28.0 & 28.5 & 26.1 & 29.4 & 29.6 & 26.4 & 0.90 & 0.50 & 0.22 & 0.31 \\
\hline
\end{tabular}

${ }^{1}$ Faecal consistency scores were performed three times a week in the first three weeks after weaning: normal faeces (score $=1$ ), soft faeces (score $=2$ ) and watery faeces (score $=3) ;{ }^{2} \mathrm{SC}=$ sanitary conditions; LSC = low sanitary conditions; HSC $=$ high sanitary conditions; ${ }^{3}$ control = basal dietary energy and amino acid $(A A)$ content; +AA = increased levels of SID AA; $+\mathrm{AA}+$ Energy $=$ increased levels of SID AA and energy; ${ }^{4} \mathrm{D}=$ dietary treatment. Values with a different letter within dietary treatment, differ at a significance level of $p<0.05$ (abc) or $p<0.10$ (wxyz).

Table 10 shows that in week 1 after weaning, the percentage of piglets with soft or watery faeces was higher in LSC pigs than HSC pigs. In week 2 and 3 after weaning, sanitary conditions did not affect the percentage of piglets with soft or watery faeces. In LSC piglets, the percentage of piglets with soft and watery faeces was higher in piglets fed the diet with increased AA + energy level than in piglets fed the diet with increased AA level in week 1 and 2 after weaning. In HSC piglets, dietary treatment did not affect the percentage of piglets with soft or watery faeces. Sex did not affect the percentage of piglets with soft or watery faeces.

The mean feacal score in week 1, 2 and 3 after weaning on Farm B is presented in Table 11. On Farm $B$, the faeces of the pigs was scored on pen level with normal faeces (score $=0$ ), soft faeces (score = 1 ), watery faeces (score $=2$ ) and extreme watery faeces (score $=3$ ) by the same person.

Table 11 Mean faecal score ${ }^{1}$ of pens with weaned piglets that were kept under different sanitary conditions (SC) and were fed diets differing in energy and essential amino acid content (Farm B).

\begin{tabular}{|c|c|c|c|c|c|c|c|c|c|c|c|c|c|}
\hline \multirow[t]{3}{*}{ Week } & \multirow[t]{3}{*}{$\mathrm{SC}^{2}$} & \multirow[t]{3}{*}{ SC } & \multicolumn{4}{|c|}{ Dietary treatment ${ }^{3}$} & \multicolumn{2}{|c|}{ Sex } & \multicolumn{5}{|c|}{ P-value } \\
\hline & & & \multirow{2}{*}{ Control } & \multirow{2}{*}{ +AA } & \multirow{2}{*}{ +Energy } & \multirow{2}{*}{ +AA+Energy } & \multirow{2}{*}{ Boar } & \multirow{2}{*}{ Gilt } & \multirow{2}{*}{ SC } & \multirow{2}{*}{$D^{4}$} & \multirow{2}{*}{ Sex } & \multirow{2}{*}{$\begin{array}{l}\text { SC } \\
\times D\end{array}$} & $\mathrm{x}$ \\
\hline & & & & & & & & & & & & & Sex \\
\hline \multirow[t]{2}{*}{1} & LSC & 0.84 & 0.81 & 0.94 & 1.00 & 0.60 & 0.75 & 0.93 & 0.14 & 0.03 & 0.14 & 0.54 & 0.26 \\
\hline & HSC & 0.45 & 0.42 & 0.49 & 0.51 & 0.37 & 0.44 & 0.46 & & & & & \\
\hline \multirow[t]{2}{*}{3} & LSC & 1.42 & 1.37 & 1.44 & 1.41 & 1.47 & 1.37 & 1.47 & 0.16 & 0.71 & 0.98 & 0.73 & 0.14 \\
\hline & HSC & 0.94 & 0.99 & 1.00 & 0.81 & 0.94 & 0.98 & 0.89 & & & & & \\
\hline
\end{tabular}

${ }^{1}$ Faecal consistency scores were performed three times a week on pen level in the first three weeks after weaning: normal faeces (score $=0$ ), soft faeces (score $=1$ ), watery faeces (score $=2$ ) and extreme watery faeces $(\operatorname{score}=3) ;{ }^{2} \mathrm{SC}=$ sanitary conditions; LSC = low sanitary conditions; HSC = high sanitary conditions; ${ }^{3}$ control = basal dietary energy and amino acid $(A A)$ content; +AA = increased levels of SID AA; +Energy = increased level of energy; +AA+Energy = increased levels of SID AA and energy; ${ }^{4} D=$ dietary treatment. Values with a different letter within dietary treatment, differ at a significance level of $p<0.05(a b c)$ or $p<0.10(x y z)$.

Table 11 shows that the mean faecal score tended to be higher in LSC piglets than in HSC piglets. In week 1 after weaning, the mean faecal score was higher in piglets fed the diet with increased AA or increased energy level than in piglets fed the diet with increased $A A+$ energy level whereas the mean faecal score in the control group was in between. In week 2 and 3 after weaning, the mean faecal 
score was not affected by dietary treatment. In week 1 and 3 after weaning, sex did not affect the mean faecal score. In week 2 after weaning, the mean faecal score was higher in LSC gilts than in LSC boars and lower in HSC gilts than HSC boars.

The wellbeing of the piglets was scored daily the first five days after weaning. On Farm A, in 15 of the 51 pens about 20 to $30 \%$ of the LSC piglets had fresh wounds for 1 or 2 days because of fighting due to mixing at weaning. In two pens, about $30 \%$ of the piglets had dirty eyes for three days and in four pens, about $30 \%$ of the piglets was sneezing for one day. In 15 pens, some piglets were shivering for 1 to 3 days. In no case it was judged necessary to intervene. On Farm B, there were no LSC and HSC piglets with fresh wounds or dirty eyes. Also, there were no sneezing and shivering piglets.

\subsection{Blood parameters}

For the purpose of regular health monitoring, on Farm B 32 piglets (four male piglets per dietary treatment per sanitary condition which means 16 HSC piglets and 16 LSC piglets) were selected for blood sampling in week 3 (batch 1 ) or week 5 (batch 2) after weaning. The blood samples were analysed on the acute phase protein haptoglobin and on antibodies against Actinobacillus pleuropneumoniae (APP), Mycoplasma hyopneumonia, PCV2 (Circovirus IgM and IgG), PPRS, Lawsonia intracellularis, Influenza A, Salmonella and Haemophilus parasuis.

The concentration of the acute phase protein haptoglobine is presented in Table 12.

Table 12 Haptoglobin concentration ( $\mathrm{g} / \mathrm{L}$ ) in blood in week 3 (batch 1) or week 5 (batch 2) after weaning in male weaned piglets that were kept under different sanitary conditions (SC) and were fed diets differing in energy and essential amino acid content (Farm B).

\begin{tabular}{|c|c|c|c|c|}
\hline & $\operatorname{LSC}^{1}$ & $\mathrm{HSC}^{1}$ & SEM ${ }^{2}$ & P-value \\
\hline Haptoglobin concentration & 0.70 & 0.45 & 0.13 & 0.21 \\
\hline
\end{tabular}

${ }^{1}$ LSC = low sanitary conditions; HSC = high sanitary conditions; ${ }^{2}$ SEM $=$ standard error of the mean

Table 12 shows that the concentration of haptoglobine was not affected by sanitary status.

In both HSC and LSC piglets, there were no piglets with positive antibody titers against Actinobacillus pleuropneumoniae (APP), Mycoplasma hyopneumonia, Lawsonia intracellularis (PIA), Salmonella and Haemophilus parasuis (Glässer).

In Figure 3, the antibody titers against PRRS are presented.

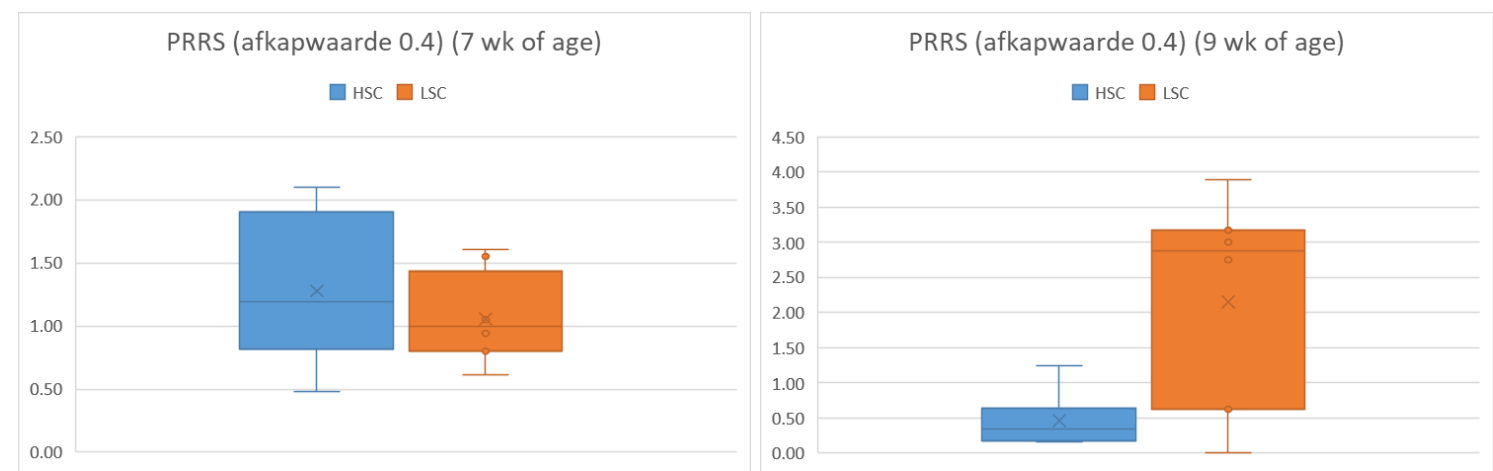

Figure 3 Antibody titers against PPRS in week 3 (batch 1) or week 5 (batch 2) after weaning in male weaned piglets that were kept under high (HSC) or low (LSC) sanitary conditions (left Figure: batch 1; right Figure: batch 2) (positive antibody titer: titer $\geq 0.4$ ) (Farm B).

In batch 1 , all HSC and LSC piglets had positive antibody titers (titer higher than 0.4) against PRRS. In the HSC piglets, this is due to the vaccination against PRRS at an age of three weeks. In the LSC piglets, the positive antibody levels may be caused by a field infection on the farm or by spreading of the vaccine virus. In batch 2 , three HSC piglets had positive antibody titers against PRRS and five 
piglets had negative antibody titers. The antibody titers, due to vaccination at an age of three weeks, are highest at an age of seven weeks and then gradually decrease resulting in piglets with negative antibody titers at an age of nine weeks. In the LSC piglets, seven piglets had positive antibody titers probably caused by a field infection.

The antibody titers against PCV2 IgG were negative in all HSC and LSC piglets. The antibody titers against PCV2 IgM are presented in Figure 4.
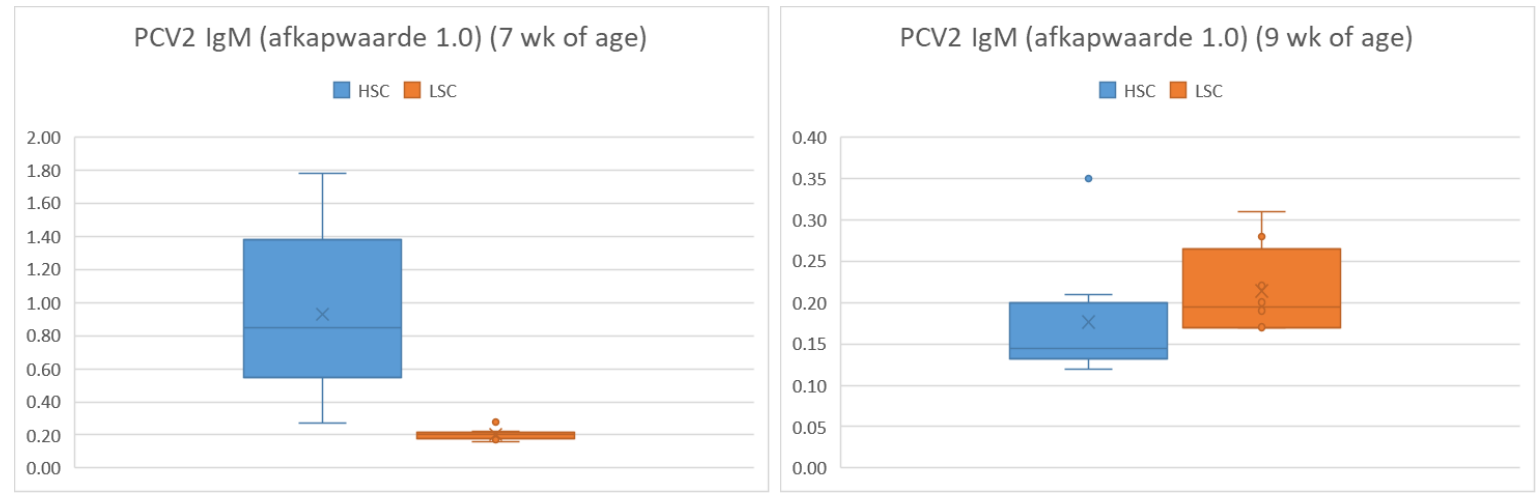

Figure 4 Antibody titers against PCV2 IgM (circo) in week 3 (batch 1) or week 5 (batch 2) after weaning in male weaned piglets that were kept under high (HSC) or low (LSC) sanitary conditions (left Figure: batch 1; right Figure: batch 2) (positive antibody titer: titer $\geq$ 1.0) (Farm B).

In batch 1 , the antibody titers against PVC2 IgM were higher in HSC piglets than in LSC piglets because the HSC piglets were vaccinated against PCV2. In batch 2, the antibody titers against PVC2 IgM were higher in LSC piglets than in HSC piglets, probably because of a starting field infection in the LSC piglets. In the HSC piglets in batch 2 the antibody titers were low. The antibody titers, due to vaccination at an age of three weeks, are highest at an age of seven weeks and then gradually decrease resulting in low antibody titers in the HSC piglets at an age of nine weeks.

In Figure 5, the antibody titers against Influenza A are presented.

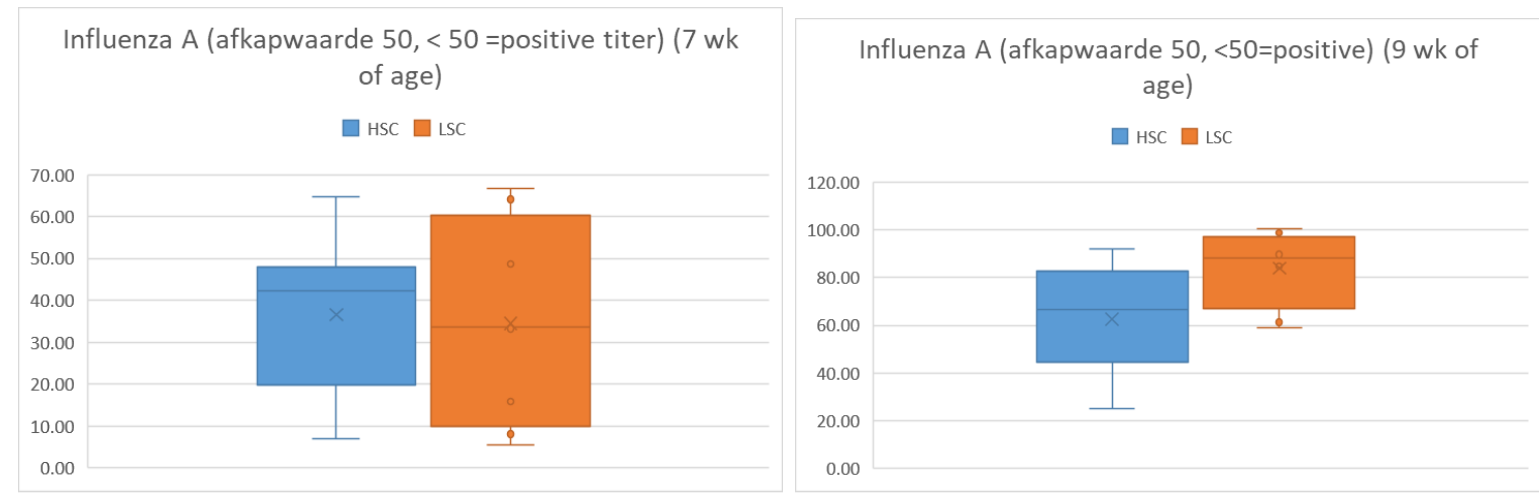

Figure 5 Antibody titers against Influenza A in week 3 (batch 1) or week 5 (batch 2) after weaning in male weaned piglets that were kept under high (HSC) or low (LSC) sanitary conditions (left Figure: batch 1; right Figure: batch 2) (positive antibody titer: titer $\leq 50.0$ ) (Farm $B)$.

In batch 1 , most HSC and LSC piglets had positive antibody titers (titer $\leq 50.0$ ) against Influenza A. Because Farm B is positive for Influenza A, positive antibody titers in the piglets might be of maternal origin. Positive antibody titers of less than 10 might be due to an active field infection. In batch 2, most HSC piglets ( 5 of the 8 piglets) and all LSC piglets had negative antibody titers (titer $>50.0$ ) against Influenza $\mathrm{A}$. 


\section{Discussion}

The aim of the present study was to evaluate the effects of increased levels of dietary energy and essential $A A$, related to the assumed increased amino acid and energy requirements in immune stimulated pigs, on the growth performance of weaned piglets. The dietary treatments were evaluated in weaned piglets kept under a low or high sanitary status regime assumed to create a contrast in degree of immune system activation in the pigs.

\section{Effect of sanitary conditions on immune status and health}

A contrast in sanitary conditions was created by imposing the pigs to differences in vaccination, cleaning and hygiene protocol and in room temperature. On Farm B, blood samples of 16 HSC piglets and 16 LSC piglets out of the 768 piglets were analysed on the acute phase protein haptoglobin and on antibodies against Actinobacillus pleuropneumoniae (APP), Mycoplasma hyopneumonia, PCV2 (Circovirus IgM and IgG), PPRS, Lawsonia intracellularis, Influenza A, Salmonella and Haemophilus parasuis. The concentration of haptoglobine did not differ significantly between LSC and HSC piglets. The concentration of haptoglobine was lower than $0.5 \mathrm{~g} / \mathrm{L}$ in $10 \mathrm{HSC}$ and 6 LSC piglets, respectively, and higher than $1.0 \mathrm{~g} / \mathrm{L}$ in 2 HSC and 3 LSC piglets, respectively. In both HSC and LSC piglets, there were no piglets with positive antibody titers against Actinobacillus pleuropneumoniae (APP), Mycoplasma hyopneumonia, Lawsonia intracellularis (PIA), Salmonella and Haemophilus parasuis (Glässer). There were no differences in the number of piglets with positive antibody titers against PRRS, PVC2 IgM and Influenza A. Although the number of animals used for measuring blood parameeters was low, these results suggest that, despite the strict contrast in cleaning-, vaccinationand hygiene protocol, there were no or only very small differences in degree of activation of the immune system between HSC and LSC piglets. These results are in line with the absence of major clinical signs of disease in the piglets on Farm B. The number of piglets that was veterinary treated was very low. The number of piglets that was veterinary treated due to leg problems, however, was higher in HSC piglets than in LSC piglets (10 vs 1 piglet; $p=0.006$ ). It is doubtful whether this is due to sanitary conditions. The mean faecal score tended to be higher (= worse) in LSC piglets than in HSC piglets on Farm B. On Farm A, no blood samples were taken for judgement of the health and immune status of the animals. The number of veterinary treated piglets did not differ significantly between the HSC and LSC piglets (17 and 23 in the HSC and LSC piglets, respectively) on Farm A. In week 1 after weaning, however, the percentage of piglets with diarrhoea was higher in LSC pigs than HSC pigs on Farm A.

\section{Effect of sanitary conditions on growth performance}

From weaning till day 35 after weaning, ADG and ADFI were similar in HSC and LSC piglets on Farm A. On Farm B, the HSC piglets showed a $8.6 \%$ higher ADG (516 vs $475 \mathrm{~g} / \mathrm{d} ; \mathrm{p}=0.27$ ) and a $3 \%$ higher ADFI (0.71 vs $0.69 \mathrm{~kg} / \mathrm{d} ; \mathrm{p}=0.34$ ). The differences in ADFI and ADG, however, were not shown to be statistically different because, due to the experimental design, SC could only be tested at room level, and not at pen level, and the number of replicates (rooms) per SC was only two. Feed conversion ratio was $4 \%$ lower (1.32 vs 1.37) in HSC piglets than in LSC piglets on Farm A and $5.5 \%$ lower (1.38 vs 1.46) on Farm B. A significant lower FCR in HSC piglets was also found by Williams et al. (1997a,b). Immune system activation due to a sanitary challenge may increase the maintenance requirement for energy with 7 to $12 \%$ and may decrease digestibility of protein and energy (reviewed by Van der PeetSchwering et al., 2019) resulting in a worse FCR in LSC pigs. Moreover, LSC pigs might prioritize the use of nutrients for immune system functioning over use for deposition in body tissues (Le Floc'h et al., 2004). Pastorelli et al. (2012) carried out a meta-analysis on 122 published experiments to quantify the feed intake and body weight gain responses of growing pigs after a sanitary challenge. They concluded that poor housing conditions reduced ADG with $16.3 \%$ (compared to unchallenged pigs), of which $4.1 \%$ was due to a lower feed intake and $12.2 \%$ to a reduced feed efficiency, so deteriorated FCR. In several studies (Williams et al., 1997a,b; Le Floc'h et al., 2009; Pastorelli et al., 2012), it was shown that immune system activation reduces ADFI and ADG. In our study, ADFI and ADG indeed were lower in LSC piglets compared to HSC piglets on Farm B. On Farm A, however, ADFI 
and ADG were similar in LSC and HSC piglets. Only a small difference in degree of immune system activation between LSC and HSC pigs might be the reason that ADFI and ADG were not affected by sanitary conditions on Farm A.

\section{Effect of increased dietary energy and amino acid levels on performance}

In several studies, it was shown that supplementation of some EAA (methionine + cysteine, threonine and tryptophan) to the diet can reduce the difference in ADG and ADFI (Le Floc'h, 2006; Trevisi et al., 2009) or FCR (Van der Meer et al., 2016; Capozzalo et al., 2017) between LSC and HSC pigs. However, despite the dietary supplementation of specific EAA, growth performance of the LSC pigs was still lower than of HSC pigs in these studies. It can be assumed that supplementation of EAA is only supporting protein retention and body weight gain if dietary energy intake is not limiting growth performance. Therefore, Van der Peet-Schwering et al. (2020) performed a study in GF pigs to evaluate the effect of both increased EAA (Lys, Met, Thr, Trp, Val and Ile) and energy levels. They concluded that an increase in contents of dietary energy and EAA increases growth performance and energy intake more in LSC than in HSC GF pigs. Compared with studies in which only EAA were supplemented to the diet without increasing dietary energy content, it seemed that dietary supplementation of both EAA and energy is more effective in increasing performance of LSC GF pigs than dietary supplementation of EAA alone. Increasing energy and selected EAA levels, might also compensate for the reduction in growth performance in LSC piglets compared to HSC piglets. We studied this at two farms.

\section{Increased $A A$ level}

An increase in only EAA level improved ADG and FCR in both LSC and HSC piglets on Farm B, whereas there was no effect on ADFI. The increase in ADG of the piglets on the diet with increased EAA compared to the control diet was 22 and $17 \mathrm{~g} / \mathrm{d}$ in LSC and HSC piglets, respectively. The FCR improved with 0.06 and 0.03 in LSC and HSC piglets, respectively. On Farm A, an increase in only EAA level improved ADG in LSC piglets with $22 \mathrm{~g} / \mathrm{d}$ compared to the control diet, whereas in HSC piglets ADG improved with only $7 \mathrm{~g} / \mathrm{d}$. The FCR improved with 0.07 and 0.05 in LSC and HSC piglets on Farm A, respectively. Thus, it can be concluded that an increase in dietary AA content improved ADG and FCR in both LSC and HSC piglets and only slightly decreased the difference in ADG and FCR between LSC and HSC piglets. These results suggest that the SID AA recommendations of CVB (2020) for piglets ( $9.2 \mathrm{~g}$ SID lysine/EW) may be below the actual requirements for maximum growth performance, also under high sanitary conditions. This applies to both farms. In Table 13, the daily SID lysine intake of the piglets on Farm A and Farm B are presented.

Table 13 Daily standardized ileal digestible lysine intake $(\mathrm{g} / \mathrm{d})$ in weaned piglets that were kept under different sanitary conditions (SC) and were fed diets differing in energy and essential amino acid content.

\begin{tabular}{|c|c|c|c|c|c|}
\hline Farm & $\operatorname{sc}^{1}$ & \multicolumn{4}{|c|}{ Dietary treatment ${ }^{2}$} \\
\hline A & LSC & 6.1 & 6.8 & - & 6.9 \\
\hline \multirow[t]{2}{*}{ B } & LSC & 7.5 & 8.3 & 7.1 & 7.7 \\
\hline & HSC & 7.6 & 8.4 & 7.5 & 7.9 \\
\hline
\end{tabular}

${ }^{1} \mathrm{SC}=$ sanitary conditions; LSC $=$ low sanitary conditions; HSC $=$ high sanitary conditions; ${ }^{2}$ control $=$ basal dietary energy and amino acid $(A A)$ content; +AA = increased levels of SID AA; +Energy = increased level of energy; +AA+Energy = increased levels of SID AA and energy.

\section{Increased energy level}

An increase in only energy level impaired ADG and energy conversion ratio (ECR) compared to the control diet in both LSC and HSC piglets on Farm B, whereas there was no effect on average daily energy intake (ADEI). The decrease in ADG was 27 and $14 \mathrm{~g} / \mathrm{d}$ in LSC and HSC piglets, respectively, compared to the control diet. The ECR worsened with 0.13 in both LSC and HSC piglets. The reason for the impaired ADG and ECR for the piglets on the diet with extra energy diet is probably a shortage of EAA. The content of SID lysine (in $\mathrm{g} / \mathrm{kg}$ ) was the same in the control diet and the diet with extra energy $(10.6 \mathrm{~g} / \mathrm{kg}$ in both the weaner and starter diet) (Table 14). The content of SID lysine (in $\mathrm{g} / \mathrm{EW}$ ), however, was lower in the diet with extra energy than in the control diet (8.2 vs $9.2 \mathrm{~g} / \mathrm{EW}$ in 
the weaner diet and 8.6 and $9.2 \mathrm{~g} / \mathrm{EW}$ in the starter diet). As the ADFI was lower on the diet with extra energy compared to the control diet $(0.67 \mathrm{vs} 0.71 \mathrm{~kg} / \mathrm{d}$ in the LSC piglets and $0.71 \mathrm{vs} 0.72 \mathrm{~kg} / \mathrm{d}$ in the HSC piglets), this resulted in a lower daily SID lysine intake in the piglets on the diet with extra energy. The daily SID lysine intake on the control diet and the diet with extra energy was 7.5 and 7.1 $\mathrm{g} / \mathrm{d}$, respectively, in the LSC piglets and 7.6 and $7.5 \mathrm{~g} / \mathrm{d}$, respectively, in the HSC piglets (Table 13).

Table 14 Standardized ileal digestible (SID) lysine content and EW in the weaner and starter.

\begin{tabular}{|c|c|c|c|c|}
\hline Diet & \multicolumn{4}{|c|}{ Dietary treatment 1} \\
\hline \multicolumn{5}{|l|}{ Weaner diet: } \\
\hline EW & 1.15 & 1.15 & 1.29 & 1.29 \\
\hline SID lysine (g/EW) & 9.2 & 10.1 & 8.2 & 9.0 \\
\hline SID lysine $(\mathrm{g} / \mathrm{kg})$ & 10.6 & 11.5 & 10.6 & 11.5 \\
\hline EW & 1.15 & 1.15 & 1.23 & 1.23 \\
\hline SID lysine (g/EW) & 9.2 & 10.0 & 8.6 & 9.3 \\
\hline
\end{tabular}

${ }^{1}$ control = basal dietary energy and amino acid $(A A)$ content; +AA = increased levels of SID AA; +Energy = increased level of energy; $+\mathrm{AA}+$ Energy $=$ increased levels of SID AA and energy.

The increase in dietary energy level did not increase the ADEI but reduced the ADFI on Farm B. Cole et al. (1972) developed a model to describe the relationship between energy concentration in the diet and ad libitum feed intake and energy intake (Figure 5). An increasing energy concentration initially will not affect the feed intake and will increase the energy intake. In this traject ( $A B$ in Figure 5), gastrointestinal fill limits feed intake (Forbes, 2009). A further increase in energy concentration, however, will reduce the feed intake and will not further increase the energy intake. In this traject (BC in Figure 5), nutrients in the blood give a satiation signal and limit feed intake (Forbes, 2009). It seems, that in our study the feed intake in both HSC and LSC piglets is limited by nutrient concentrations in the blood (chemical satiation). It can be concluded that only increasing the energy level in the diet and not the AA level does not improve the growht performance of both LSC and HSC piglets.

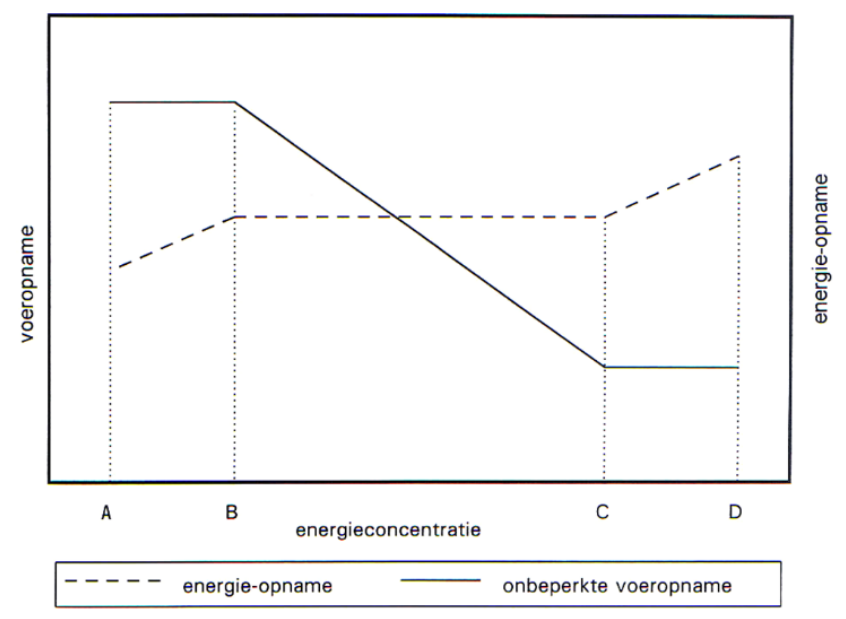

Figure 5 Schematic representation of ad libitum feed intake and energy intake in relation to energy concentration in the feed (Cole et al., 1972). In traject AB, gastrointestinal fill limits feed intake. In traject $B C$, nutrients in the blood give a satiation signal and limit feed intake.

Increased EAA and energy level

An increase in both EAA and energy level increased ADG (437 vs $416 \mathrm{~g} / \mathrm{d}$ ) and ADEI (0.73 vs 0.67 $E W / d$ ) compared to the control group in LSC piglets on Farm A, but did not affect ADG and ADEI in HSC piglets. On the control diet, ADG of the HSC piglets was $13 \mathrm{~g} / \mathrm{d}$ higher than of the LSC piglets (429 vs $416 \mathrm{~g} / \mathrm{d}$ ) on Farm A whereas on the diet with increased EAA and energy level, ADG of the HSC piglets was $17 \mathrm{~g} / \mathrm{d}$ lower than of the LSC piglets (420 vs $437 \mathrm{~g} / \mathrm{d}$ ). The effects on FCR and ECR were 
similar in LSC and HSC pigs. Feed conversion ratio was improved with 0.06 in both LSC and HSC piglets, but ECR worsened with 0.05 in both LSC and HSC piglets fed the energy and AA supplemented diets. Thus, it seems that an increase in both AA and energy level increased ADG and energy intake more in LSC than in HSC piglets on Farm A. Similar results were found by Van der Peet-Schwering et al. (2020) in a study with GF pigs. They also concluded that an increase in dietary energy and amino acid content increased ADG and energy intake more in LSC than in HSC pigs whereas the effect on FCR and ECR were similar in LSC and HSC GF pigs. Moreover, Van der Peet-Schwering et al. (2020) concluded that dietary supplementation of both EAA and energy seems more effective in increasing performance of LSC GF pigs than dietary supplementation of EAA alone. They assumed that supplementation of EAA is only supporting protein retention and body weight gain if dietary energy intake is not limiting. In our study, however, on Farm A ADG was similar in LSC piglets that were fed diets with increased EAA or diets with increased EAA + energy levels. The daily SID lysine intake was similar in LSC piglets on both diets $(6.8 \mathrm{~g} / \mathrm{d}$ on the diet with increased EAA and $6.9 \mathrm{~g} / \mathrm{d}$ on the diet wiht increased EAA + energy), whereas the ADEI was higher on the diet with increased EAA + energy levels $(0.73$ vs $0.68 \mathrm{EW} / \mathrm{d})$. It seems that energy intake was not limiting protein retention and ADG in the LSC piglets on the diet with only increased EAA levels. In the HSC piglets on Farm A, ADEI was similar in piglets fed the diets with increased EAA or increased EAA + energy levels whereas ADG was $16 \mathrm{~g} / \mathrm{d}$ lower (420 vs $436 \mathrm{~g} / \mathrm{d}$ ) in piglets fed the diet with increased EAA + energy level. The lower ADG is probably caused by a lower daily SID lysine intake of the piglets fed the diet with increased EAA + energy level ( $6.3 \mathrm{vs} 6.6 \mathrm{~g} / \mathrm{d}$ ). Thus, it can be concluded that dietary supplementation of both EAA and energy on Farm $A$ is equally or even less effective in increasing performance in both LSC and HSC piglets than dietary supplementation of EAA alone.

On Farm B, an increase in both EAA and energy level did not improve ADEI and ADG compared to the control diet in both LSC and HSC piglets, whereas ECR worsened with 0.07 in both LSC and HSC piglets. Similar results were found in HSC piglets on Farm A. In LSC piglets on Farm A, however, an increase in both EAA and energy level increased ADEI and ADG compared to the control diet. On Farm $A$, the ADEI in LSC piglets fed the control diet was much lower than in LSC piglets fed the control diet on Farm B ( 0.67 vs $0.83 \mathrm{EW} / \mathrm{d})$. On Farm A, the increase in dietary energy level did not affect the feed intake but increased the energy intake (gastrointestinal fill limits feed intake; traject AB in Figure 5) in LSC piglets. On Farm B, however, the increase in dietary energy reduced the feed intake and did not increase the energy intake (nutrients in the blood give a satiating signal and limit feed intake; traject BC in Figure 5) in LSC piglets. Thus, it seems that on Farm A, gastrointestinal fill limits feed intake in LSC piglets whereas on Farm B, nutrient levels in the blood seem to limit feed intake in LSC piglets. Because of the reduction in feed intake of the LSC piglets fed the diet with increased EAA + energy level on Farm B, the daily SID lysine intake was similar in LSC piglets fed the control diet or the diet with increased EAA + energy levels (Table 13) resulting in a similar ADG. It is not clear why on Farm $A, A D F I$ and ADEI are lower in HSC than LSC piglets fed the diet with increased EAA + energy level. On Farm $B$, in both LSC and HSC piglets ADEI was similar in piglets fed the diets with increased EAA or increased EAA + energy levels whereas ADG was lower in piglets fed the diet with increased EAA + energy level. The lower ADG is probably caused by a lower daily SID lysine intake of the piglets fed the diet with increased EAA + energy level. Thus, it can be concluded that dietary supplementation of both EAA and energy on Farm $B$ is less effective in increasing performance in both LSC and HSC piglets than dietary supplementation of EAA alone.

The levels of supplementation of EAA and energy in the diets with increased levels of EAA or EAA + energy compared to the control diet were based on the use of a calculation model for GF pigs as described by van der Peet-Schwering et al. (2019). The model was adjusted for use in piglets by modifying the energy requirements for maintenance purposes (470 kJ ME per $\mathrm{kg}^{0.75}$; Le Dividich and Seve, 2001) and the factor for the efficiency of utilization of tryptophan (from 0.57 to 0.50 ) to prevent presence of excess of tryptophan in the non-challenged scenario (without sanitary challenge). Using a factorial approach for calculating requirements for protein and energy deposition, with the model the effects of low sanitary conditions on the EAA and energy requirements of pigs were estimated and translated into adjusted optimal dietary energy and EAA levels. This information was used to formulate the EAA and energy enriched diets. Regarding the original assumptions about the quantitative effects of sanitary conditions on feed intake ( $-4 \%$ in LSC piglets), used for calculating adjusted nutrient concentrations in the energy and EAA supplemented diets, it can be concluded that effects on feed intake in the present study were not in line with the original assumption, as we found no difference in 
ADFI between LSC and HSC piglets. Moreover, an increase in energy level of the diet may not result in an increase in ADEI in both LSC and HSC piglets because of a reduction in ADFI. The assumed effects of sanitary status on the post absorptive utilization of particular amino acids (Trp, Val, Leu and Ile) and the increased maintenance requirement for energy in pigs kept under low sanitary conditions cannot be compared directly as both parameters were not measured in the current study. They might only be reflected indirectly in the response of the pigs in terms of growth performance and feed conversion ratio. The SID AA recommendations of CVB (2020) for piglets ( $9.2 \mathrm{~g}$ SID lysine/EW) as used in the control diet may be below the actual requirements for maximum growth performance, also under high sanitary conditions. Overall, this suggests that further validation of the SID AA requirement in piglets is necessary. Moreover, further validation of the calculation model for adjusting dietary nutrient concentrations in relation to health status of piglets is required using different environmental and/or challenge conditions. 


\section{$5 \quad$ Conclusions}

The aim of the present study was to evaluate the effects of increasing dietary concentration of energy and EAA on the growth performance of weaned piglets kept under low (LSC) and high sanitary conditions (HSC). The main conclusions are:

Sanitary conditions:

- Despite the contrast in cleaning-, vaccination- and hygiene protocol, based on blood serology no or only very small differences in degree of activation of the immune system between HSC and LSC pigs were observed.

- $\quad$ From weaning till day 35 after weaning, ADG and ADFI were similar in HSC and LSC piglets on Farm A. On Farm B, the HSC piglets showed a numerically $8.6 \%$ higher ADG (516 vs $475 \mathrm{~g} / \mathrm{d}$ ) and $3 \%$ higher ADFI ( 0.71 vs $0.69 \mathrm{~kg} / \mathrm{d}$ ). Feed conversion ratio was $4 \%$ lower (1.32 vs 1.37 ) in HSC piglets than in LSC piglets on Farm A and 5.5\% lower (1.38 vs 1.46) on Farm B.

- Sanitary conditions did not affect the number of culled piglets. The number of veterinary treated piglets did not differ between HSC and LSC piglets on Farm A. On Farm B, however, the number of piglets that was veterinary treated due to leg problems was higher in HSC piglets. The occurrence of diarrhea was higher in LSC piglets than in HSC piglets on both farms, especially in week 1 after weaning.

Increased amino acid content:

- $\quad$ An increase in dietary EAA content for Lys, Met, Thr, Trp, Val and Ile improved ADG and FCR in both LSC and HSC piglets. However, it only slightly decreased the difference in ADG and FCR between LSC and HSC piglets. This applies to both farms.

Increased energy content:

- An increase in only energy level did not improve the performance of both LSC and HSC piglets. The increase in dietary energy level did not increase the average daily energy intake (ADEI) but reduced the ADFI resulting in an impaired ADG and energy conversion ratio (ECR).

Increased energy and amino acid content:

- $\quad$ An increase in both EAA and energy level increased ADG (437 vs $416 \mathrm{~g} / \mathrm{d}$ ) and ADEI (0.73 vs $0.67 \mathrm{EW} / \mathrm{d}$ ) compared to the control group in LSC piglets on Farm A, but did not affect ADG and ADEI in HSC piglets.

- $\quad$ On Farm B, an increase in both EAA and energy level did not improve ADEI and ADG compared to the control diet in both LSC and HSC piglets.

- On both farms, feed conversion ratio was improved but ECR was impaired in piglets fed the energy and AA supplemented diets compared to the control group. The effects on FCR and ECR were similar in LSC and HSC pigs.

- $\quad$ Dietary supplementation of both EAA and energy was no more or even less effective in increasing performance in both LSC and HSC piglets than dietary supplementation of EAA alone. This applies to both farms.

Overall, it can be concluded that an increase in contents of only dietary EAA (Lys, Met, Thr, Trp, Val and Ile) improved ADG and FCR in both LSC and HSC piglets. It only slightly decreased, however, the difference in ADG and FCR between LSC and HSC piglets. These results suggest that the SID AA recommendations of CVB (2020) for piglets (9.2 g SID lysine/EW) may be below the actual requirements for maximum growth performance of piglets, also under high sanitary conditions. An increase in only dietary energy level did not improve the performance of both LSC and HSC piglets. Dietary supplementation of both EAA and energy was equally or even less effective in increasing performance in both LSC and HSC piglets than dietary supplementation of EAA alone. 


\section{References}

AgroVision. 2017. Kengetallenspiegel 2016. Bedrijfsvergelijking AgroVision B.V.

Capozzalo, M.M., J.C. Kim, J.K. Htoo, C.F.M. de Lange, B.P. Mullan, C.F. Hansen, J.W. Resink and J.R. Pluske. 2017. Pigs experimentally infected with an enterotoxigenic strain of Escherichia coli have improved feed efficiency and indicators of inflammation with dietary supplementation of tryptophan and methionine in the immediate post-weaning period. Animal Production Science, 57, 935-947.

Centraal Veevoederbureau. 2020. Tabellenboek Voeding Varkens 2020. CVB-reeks nr. 63.

Cole, D.J.A., B. Hardy and D. Lewis 1972. Nutrient density of pig diets. In: Pig production (ed. D.J.A. Cole), 243-257, Butterworths, London.

Forbes, J.M. 2009. Integration of pre- and post-absorptive factors in feed intake regulation and predition with particular respect to the pigs. In: Voluntary feed intake in pigs. Eds D. Torrallardona and E. Roura, 61-86.

GenStat. 2018. GenStat for Windows 18th Edition. VSN International Ltd. Hemel Hempstead, UK.

Gerritsen, R., P. van der Aar, P. and F. Molist. 2012. Insoluble nonstarch polysaccharides in diets for weaned piglets. Journal of Animal Science, 90, 318-320.

Klasing, K.C. and B.J. Johnstone. 1991. Monokines in growth and development. Poultry Science, 70, 1781-1789.

Le Dividich, J. and B. Seve. 2001. Energy requirements of the young pig. The Weaner pig: nutrition and management, pp.17-44.

Le Floc'h, N. 2006. Gepubliceerd in Orffa "Invloed van de gezondheidsstatus en het verbod op AMGB op de aminozuurbehoefte van varkens".

Le Floc'h, N., D. Melchior and C. Obled. 2004. Modifications of protein and amino acid metabolism during inflammation and immune system activation. Livestock Production Science, 87, 37-45.

Le Floc'h, N., L. LeBellego, J.J. Matte, D. Melchior, and B. Sève. 2009. The effect of sanitary status degradation and dietary tryptophan content on growth rate and tryptophan metabolism in weaning pigs. Journal of Animal Science, 87, 1686-1694.

Pastorelli, H., J. van Milgen, P. Lovatto, and L. Montagne. 2012. Meta-analysis of feed intake and growth responses of growing pigs after a sanitary challenge. Animal, 6, 952-961.

Petersen, H.H., A.K. Ersboll, C.S. Jensen and J.P. Nielsen. 2002. Serum-haptoglobin concentration in Danish slaughter pigs of different health status. Preventive Veterinary Medicine, 54, 325-335.

Piñeiro, C., M. Piñeiro, J. Morales, M. Andrés, E. Lorenzo, M. del Pozo, M.A. Alava and F. Lampreave. 2009. Pig-MAP and haptoglobin concentration reference values in swine from commercial farms. The Veterinary Journal, 179, 78-84.

Piñeiro, M., J. Morales, E. Vizcaíno, J.A. Murillo, Th. Klauke, B.Petersen, C.Piñeiro. 2013. The use of acute phase proteins for monitoring animal health and welfare in the pig production chain: The validation of an immunochromatographic method for the detection of elevated levels of pig-MAP. Meat Science, 95, 712-718.

Spurlock, M.E. 1997. Regulation of metabolism and growth during immune challenge: an overview of cytokine function. Journal of Animal Science, 75, 1773-1783.

Trevisi, P., D. Melchior, M. Mazzoni, L. Casini, S. De Filippi, L. Minieri, G. Lalatta-Costerbosa and P. Bosi. 2009. A tryptophan-enriched diet improves feed intake and growth performance of susceptible weanling pigs orally challenged with Escherichia coli K88. Journal of Animal Science, $87,148-156$.

Van der Meer, Y., A. Lammers, A.J.M. Jansman, M.M.J.A. Rijnen, W.H. Hendriks, and W.J.J. Gerrits. 2016. Performance of pigs kept under different sanitary conditions affected by protein intake and amino acid supplementation., Journal of Animal Science, 94, 4704-4719.

Van der Meer, Y. 2017. Nutrition of pigs kept under low and high sanitary conditions. PhD Dissertation, Wageningen University, Wageningen, the Netherlands.

Van der Peet-Schwering, C.M.C., S.J. Koopmans and A.J.M. Jansman. 2019. Amino acid requirements in relation to health status in growing and finishing pigs. Report 1168, Wageningen Liverstock Research, Wageningen. 
Van der Peet-Schwering, C.M.C., R.G.J.A. Verheijen, G.P. Binnendijk and A.J.M. Jansman. 2020. Amino acid and energy requirements of growing-finishing pigs kept under low and high sanitary conditions. Report 1248, Wageningen Livestock Research, Wageningen.

Williams, N.H., T.S. Stahly and D.R. Zimmerman. 1997a. Effect of chronic immune system activation on body nitrogen retention, partial efficiency of lysine uitlization, and lysine needs of pigs. Journal of Animal Science, 75, 2472-2480.

Williams, N.H., T.S. Stahly and D.R. Zimmerman. 1997b. Effect of level of chronic immune system activation on the growth and dietary lysine needs of pigs fed from 6 to $112 \mathrm{~kg}$. Journal of Animal Science, 75, 2481-2496. 


\section{Appendix 1 Starting points to calculate the increased energy and SID EAA levels}

- The adjustments for essential amino acid (EAA) and energy of the experimental diets were based on the calculation model as described for growing-finishing pigs in Van der PeetSchwering et al., 2019.

- $\quad$ The model was adjusted for use in piglets by modifying the energy requirements for maintenance purposes (470 kJ ME per $\mathrm{kg}^{0.75}$; Le Dividichand Seve, 2001) and the factor for the efficiency of utilization of Trp (from 0.57 to 0.50 ) to prevent presence of excess of Trp in the basal, non-challenged scenario (without sanitary challenge). The efficiency of utilization of Met + Cys was set at 0.51 (similar to the value used in InraPorc).

- $\quad$ The model was used to calculate required adjustments in levels of EAA and/or NE (EW) considering effects of low sanitary conditions on amino acid and energy requirements in the weaning ( $\mathrm{d}$ 0-9 post-weaning) and starter phase ( $\mathrm{d}$ 9-35 post weaning).

- $\quad$ The settings for parameters in the model for both phases, and the settings used in the model for growing pigs as reference, are given in the table below (Table A).

- $\quad$ In Table $B$ and $C$ the calculated dietary adjustments for EAA and energy are given for both phases. As L-Leu and L-His are not largely available for use in commercial diets, the concentrations of both amino acids on an SID basis were not included/taken into account in the adjusted diets although the model calculations indicated a deficiency for these amino acids in the scenario low sanitary conditions.

Table A. Settings for parameters in the model for calculating dietary adjustments for EAA and energy in both experimental phases of the study with weaned piglets challenged by sanitary conditions (weaning phase (speenvoer) and starter phase (startvoer))

\begin{tabular}{|c|c|c|c|c|}
\hline & & \multicolumn{3}{|c|}{ Speenvoer Startvoer } \\
\hline \multicolumn{2}{|l|}{ Gem. lichaamsgewicht (kg) } & 50 & 8.5 & 17.5 \\
\hline \multicolumn{2}{|l|}{ Gem voeropname $(\mathrm{kg} / \mathrm{d})$} & & 0.300 & 0.820 \\
\hline Feed intake & rel. to HSC (ref. = 1.00) & 0.96 & 0.95 & 0.96 \\
\hline Dig. AA (SID) & rel. to HSC (ref. = 1.00) & 0.96 & 0.96 & 0.96 \\
\hline Dig. Energy (faecal) & rel. to HSC (ref. = 1.00) & 0.96 & 0.98 & 0.98 \\
\hline Immune proteins & $\mathrm{mg} / \mathrm{kg} / \mathrm{d}$ & 50 & 25 & 25 \\
\hline Immune proteins & $\mathrm{mg} / \mathrm{d}$ & 2500 & 213 & 438 \\
\hline Energy req. Maintenance & rel. to HSC (ref. = 1.00) & 1.08 & 1.10 & 1.10 \\
\hline AA efficiency overall & rel. to HSC (ref. = 1.00) & 1.00 & 1.00 & 1.00 \\
\hline Eff. Trp, Val, lle and Leu & rel. to HSC (ref. = 1.00) & 0.96 & 0.96 & 0.96 \\
\hline Max. protein deposition & rel. to HSC (ref. = 1.00) & 1.00 & 1.00 & 1.00 \\
\hline \multicolumn{2}{|c|}{ Marginal ratio (ratio fat to protein deposition; TMV) } & 1.28 & 0.43 & 0.81 \\
\hline
\end{tabular}

TMV = Technisch Model Varkensvoeding 
Table B. Calculated dietary adjustments for SID EAA $(\mathrm{g} / \mathrm{kg})$ and energy $(E W)$ in the weaning (speen) phase.

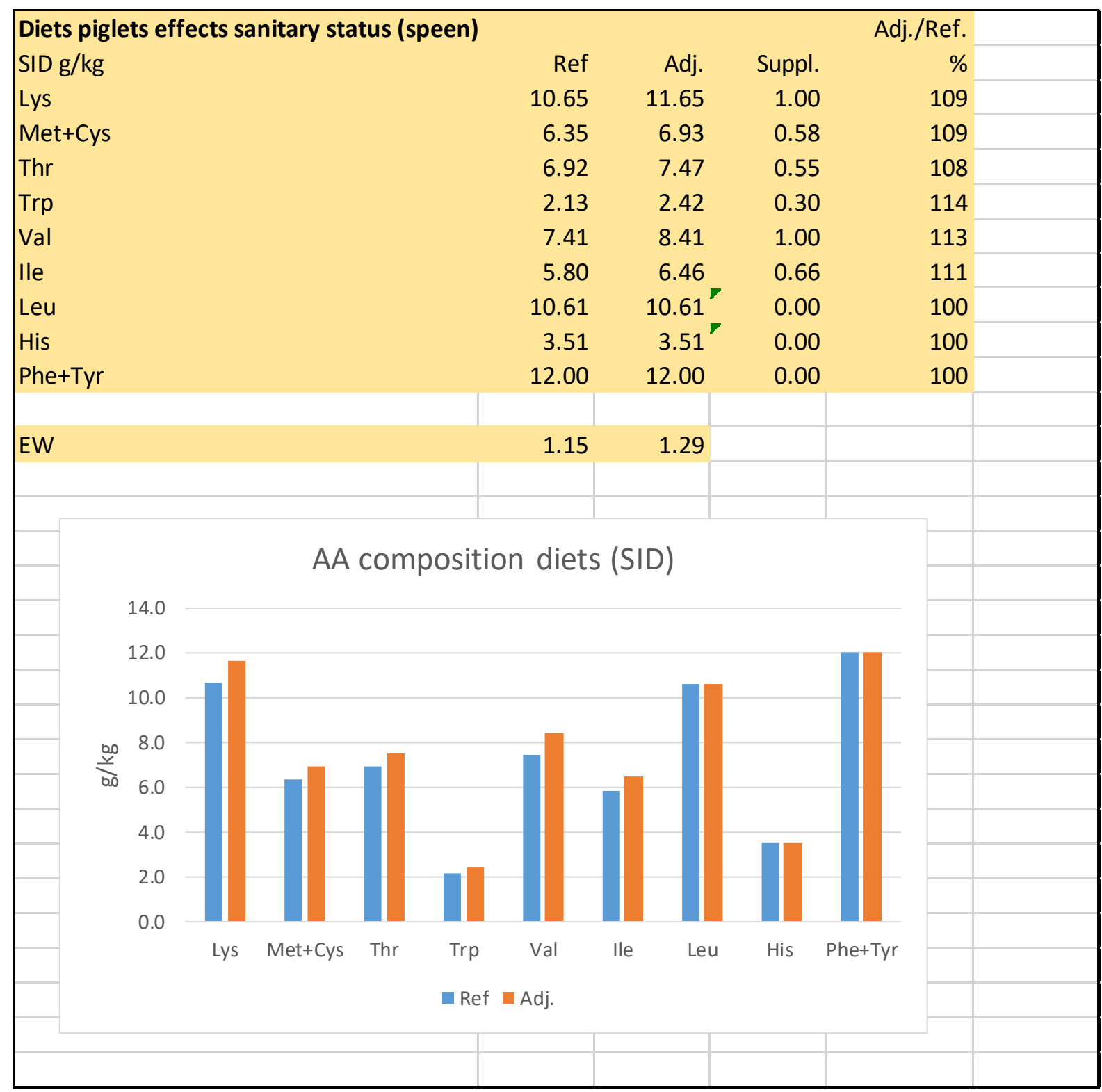


Table C. Calculated dietary adjustments for SID EAA $(\mathrm{g} / \mathrm{kg})$ and energy (EW) in the starter (opfok) phase.

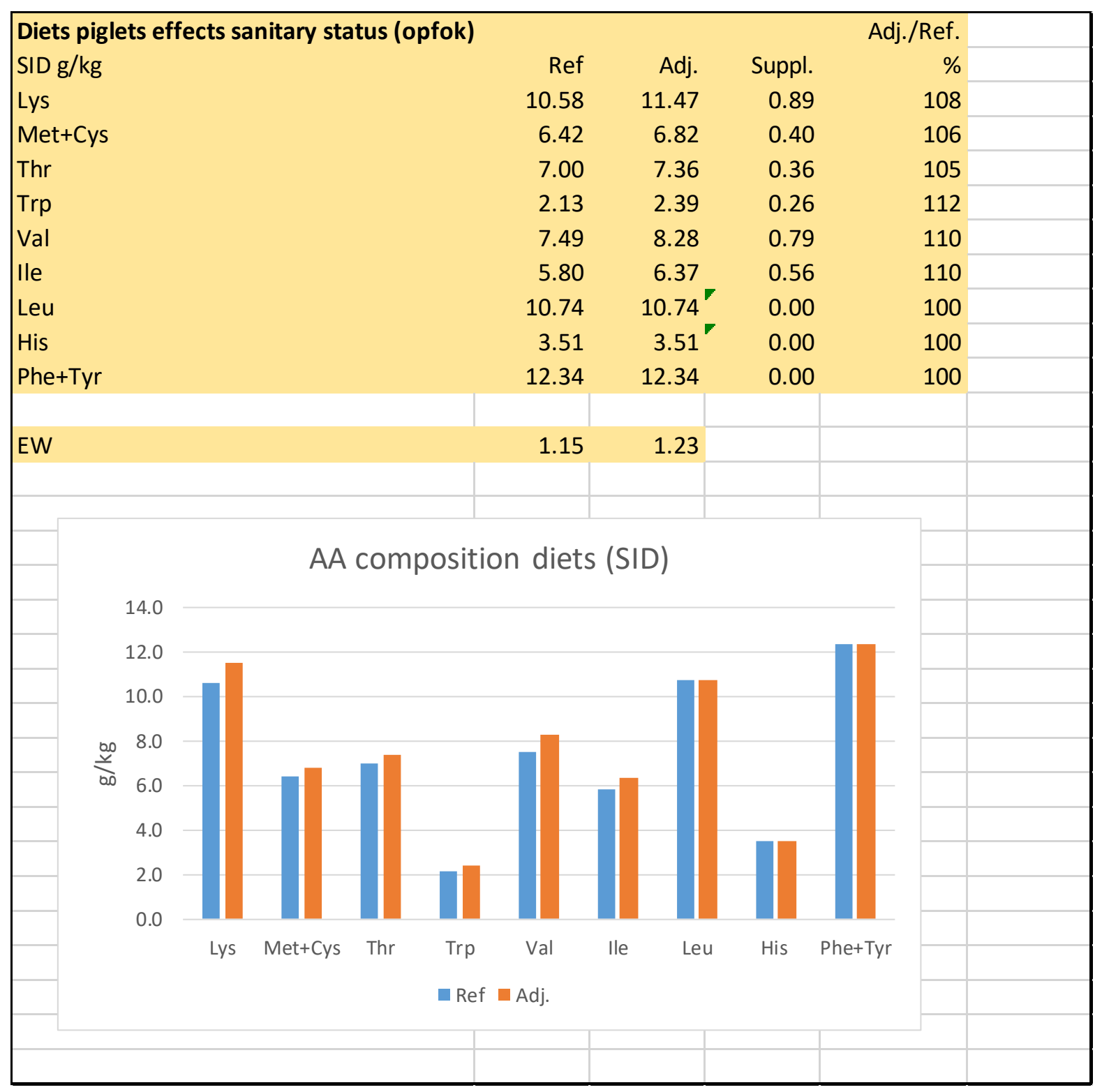




\section{Appendix 2 Composition of the experimental diets}

Weaner diets

\begin{tabular}{|c|c|c|c|c|c|}
\hline & & Control & $+\mathbf{A A}$ & + Energy & $\begin{array}{l}+\mathbf{A A}+ \\
\text { Energy }\end{array}$ \\
\hline \multicolumn{6}{|l|}{ Ingredient, \% } \\
\hline BARLEY & & 30.000 & 30.000 & 30.000 & 30.000 \\
\hline WHEAT & & 22.803 & 21.936 & 20.705 & 20.020 \\
\hline CORN HEAT TREATED & & 5.000 & 5.000 & 5.000 & 5.000 \\
\hline WHEAT MIDDLINGS & & 6.000 & 6.000 & 6.000 & 6.000 \\
\hline BREADMEAL & & 1.990 & 2.000 & 2.000 & 2.000 \\
\hline RAPE OIL & & 0.000 & 0.000 & 1.785 & 1.773 \\
\hline SOY BEAN OIL & & 0.500 & 0.500 & 3.000 & 3.000 \\
\hline GLYCERIN 85\% & & 1.000 & 1.000 & 1.000 & 1.000 \\
\hline SALMON OIL & & 0.400 & 0.400 & 0.400 & 0.400 \\
\hline POTATO PROTEIN & & 2.000 & 2.000 & 2.000 & 2.000 \\
\hline CHICORY PULP & & 1.500 & 1.500 & 1.500 & 1.500 \\
\hline OAT HULLS & & 5.000 & 5.000 & 2.000 & 2.000 \\
\hline SPC SOYCOMIL R & & 5.501 & 5.754 & 6.033 & 6.080 \\
\hline SOY BEANS HEAT TREATED & & 8.000 & 8.000 & 8.000 & 8.000 \\
\hline SACCHAROSE (SUGAR) & & 2.000 & 2.000 & 2.000 & 2.000 \\
\hline WHEY POWDER SWEET & & 3.508 & 3.508 & 3.508 & 3.508 \\
\hline MONO CALCIUM PHOSPHATE & & 0.668 & 0.665 & 0.962 & 0.963 \\
\hline LIME FINE & & 0.373 & 0.338 & 0.420 & 0.382 \\
\hline SALT VACUUM & & 0.487 & 0.487 & 0.463 & 0.463 \\
\hline px PIGLET BASIS 2\% & & 1.980 & 1.980 & 1.980 & 1.980 \\
\hline DL-METHIONINE & & 0.160 & 0.212 & 0.158 & 0.217 \\
\hline L-LYSINE HCL & & 0.446 & 0.563 & 0.431 & 0.556 \\
\hline L-TRYPTOPHAN & & 0.179 & 0.316 & 0.174 & 0.318 \\
\hline L-THREONINE & & 0.156 & 0.208 & 0.152 & 0.207 \\
\hline CITRIC ACID & & 0.200 & 0.200 & 0.200 & 0.200 \\
\hline ILE-VAL BLEND (90-10) & & & 0.066 & & 0.065 \\
\hline VALINE $40 \%$ PX & & 0.149 & 0.366 & 0.129 & 0.369 \\
\hline Nutrient & Unit & & & & \\
\hline Crude protein & $\%$ & 16.7 & 17.1 & 16.7 & 17.0 \\
\hline Crude fat Berntrop & $\%$ & 4.6 & 4.6 & 8.8 & 8.8 \\
\hline Crude fat & $\%$ & 3.9 & 3.9 & 8.2 & 8.1 \\
\hline Crude fibre & $\%$ & 5.3 & 5.3 & 4.3 & 4.3 \\
\hline Ash & $\%$ & 5.2 & 5.2 & 5.3 & 5.3 \\
\hline Moisture & $\%$ & 9.1 & 9.0 & 8.6 & 8.6 \\
\hline Dry matter & $\%$ & 90.9 & 91.0 & 91.4 & 91.4 \\
\hline Starch Ewers & $\%$ & 37.4 & 36.9 & 36.0 & 35.7 \\
\hline Sugar & $\%$ & 7.7 & 7.7 & 7.6 & 7.6 \\
\hline NE swine & MJ & 10.12 & 10.12 & 11.35 & 11.35 \\
\hline EW & - & 1.15 & 1.15 & 1.29 & 1.29 \\
\hline dP standard swine & $\%$ & 0.44 & 0.44 & 0.49 & 0.49 \\
\hline sid LYS sw & $\%$ & 1.06 & 1.16 & 1.06 & 1.16 \\
\hline sid MET sw & $\%$ & 0.39 & 0.44 & 0.39 & 0.44 \\
\hline sid CYS sw & $\%$ & 0.25 & 0.25 & 0.25 & 0.25 \\
\hline sid $M+C$ sw & $\%$ & 0.64 & 0.69 & 0.63 & 0.69 \\
\hline
\end{tabular}




\begin{tabular}{|c|c|c|c|c|c|}
\hline sid THR sw & $\%$ & 0.69 & 0.75 & 0.69 & 0.75 \\
\hline sid TRP sw & $\%$ & 0.21 & 0.24 & 0.21 & 0.24 \\
\hline sid VAL sw & $\%$ & 0.74 & 0.84 & 0.74 & 0.84 \\
\hline sid ARG sw & $\%$ & 0.87 & 0.88 & 0.88 & 0.88 \\
\hline sid ISO sw & $\%$ & 0.59 & 0.65 & 0.59 & 0.65 \\
\hline sid LEU sw & $\%$ & 1.06 & 1.07 & 1.07 & 1.07 \\
\hline sid HIS sw & $\%$ & 0.35 & 0.35 & 0.35 & 0.35 \\
\hline sid $\mathrm{P}+\mathrm{T}$ sw & $\%$ & 1.20 & 1.21 & 1.21 & 1.21 \\
\hline sid PHE sw & $\%$ & 0.70 & 0.71 & 0.71 & 0.71 \\
\hline sid TYR sw & $\%$ & 0.50 & 0.51 & 0.51 & 0.51 \\
\hline sid MET/LYS sw & - & 0.36 & 0.38 & 0.36 & 0.38 \\
\hline sid CYS/LYS sw & - & 0.24 & 0.22 & 0.23 & 0.21 \\
\hline sid $M+C / L Y S$ sw & - & 0.60 & 0.59 & 0.60 & 0.59 \\
\hline sid THR/LYS sw & - & 0.65 & 0.64 & 0.65 & 0.64 \\
\hline sid TRP/LYS sw & - & 0.20 & 0.21 & 0.20 & 0.21 \\
\hline sid VAL/LYS sw & - & 0.70 & 0.72 & 0.70 & 0.72 \\
\hline sid ARG/LYS sw & - & 0.82 & 0.76 & 0.83 & 0.76 \\
\hline sid ISO/LYS sw & - & 0.55 & 0.55 & 0.56 & 0.55 \\
\hline sid LEU/LYS sw & - & 1.00 & 0.92 & 1.01 & 0.92 \\
\hline sid HIS/LYS sw & - & 0.33 & 0.30 & 0.33 & 0.30 \\
\hline sid $P+T / L Y S$ sw & - & 1.13 & 1.04 & 1.14 & 1.04 \\
\hline LYS - Lysine & $\%$ & 1.17 & 1.27 & 1.17 & 1.27 \\
\hline MET - Methionine & $\%$ & 0.42 & 0.47 & 0.41 & 0.47 \\
\hline CYS - Cystine & $\%$ & 0.29 & 0.29 & 0.29 & 0.29 \\
\hline$M+C-$ Met + Cys & $\%$ & 0.71 & 0.76 & 0.70 & 0.76 \\
\hline THR - Threonine & $\%$ & 0.77 & 0.82 & 0.77 & 0.82 \\
\hline TRP - Tryptophan & $\%$ & 0.24 & 0.27 & 0.24 & 0.27 \\
\hline ISO - Isoleucine & $\%$ & 0.66 & 0.72 & 0.67 & 0.72 \\
\hline PHE - Phenylalanine & $\%$ & 0.79 & 0.80 & 0.79 & 0.79 \\
\hline HIS - Histidine & $\%$ & 0.39 & 0.39 & 0.39 & 0.39 \\
\hline LEU - Leucine & $\%$ & 1.22 & 1.23 & 1.23 & 1.23 \\
\hline TYR - Tyrosine & $\%$ & 0.56 & 0.57 & 0.57 & 0.57 \\
\hline VAL - Valine & $\%$ & 0.84 & 0.94 & 0.84 & 0.94 \\
\hline Calcium & $\%$ & 0.55 & 0.55 & 0.62 & 0.62 \\
\hline Phosphorus, total & $\%$ & 0.52 & 0.52 & 0.58 & 0.58 \\
\hline Sodium & $\%$ & 0.26 & 0.26 & 0.25 & 0.25 \\
\hline Chlorine & $\%$ & 0.57 & 0.59 & 0.55 & 0.57 \\
\hline Potassium & $\%$ & 0.75 & 0.75 & 0.74 & 0.74 \\
\hline Cu tot & $\mathrm{mg} / \mathrm{kg}$ & 140 & 140 & 140 & 140 \\
\hline $\mathrm{Zn}$ tot & $\mathrm{mg} / \mathrm{kg}$ & 137 & 137 & 137 & 137 \\
\hline $\mathrm{Mn}$ tot & $\mathrm{mg} / \mathrm{kg}$ & 53 & 53 & 51 & 51 \\
\hline Vit A & $\mathrm{IU} / \mathrm{kg}$ & 16000 & 16000 & 16000 & 16000 \\
\hline Vit D3 & $\mathrm{IU} / \mathrm{kg}$ & 1000 & 1000 & 1000 & 1000 \\
\hline Vit E & $\mathrm{mg} / \mathrm{kg}$ & 100 & 100 & 100 & 100 \\
\hline
\end{tabular}




\begin{tabular}{|c|c|c|c|c|c|}
\hline & & Control & $+\mathbf{A A}$ & + Energy & $\begin{array}{l}\text { + AA + } \\
\text { Energy }\end{array}$ \\
\hline \multicolumn{6}{|l|}{ Ingredient, $\%$} \\
\hline BARLEY & & 35.000 & 35.000 & 35.000 & 35.000 \\
\hline WHEAT & & 20.414 & 19.792 & 15.913 & 15.293 \\
\hline CORN HEAT TREATED & & 5.000 & 5.000 & 5.000 & 5.000 \\
\hline WHEAT MIDDLINGS PELLET & & 6.000 & 6.000 & 6.000 & 6.000 \\
\hline BREADMEAL & & 5.000 & 5.000 & 5.000 & 5.000 \\
\hline RAPE OIL & & 0.000 & 0.000 & 1.611 & 1.590 \\
\hline SOY BEAN OIL & & 0.533 & 0.512 & 2.000 & 2.000 \\
\hline GLYCERIN 85\% (NA) & & 1.000 & 1.000 & 1.000 & 1.000 \\
\hline SALMON OIL & & 0.400 & 0.400 & 0.400 & 0.400 \\
\hline POTATO PROTEIN & & 2.000 & 2.000 & 2.000 & 2.000 \\
\hline CHICORY PULP & & 1.000 & 1.000 & 1.000 & 1.000 \\
\hline OAT HULLS & & 3.000 & 3.000 & 3.000 & 3.000 \\
\hline SOY BEAN MEAL HIPRO & & 10.000 & 10.000 & 10.000 & 10.000 \\
\hline SOY BEANS HEAT TREATED & & 4.445 & 4.555 & 5.700 & 5.809 \\
\hline SACCHAROSE (SUGAR) & & 1.500 & 1.500 & 1.500 & 1.500 \\
\hline MONO CALCIUM PHOSPHATE & & 0.389 & 0.388 & 0.528 & 0.527 \\
\hline LIME FINE & & 0.562 & 0.532 & 0.603 & 0.573 \\
\hline SALT VACUUM & & 0.472 & 0.472 & 0.473 & 0.473 \\
\hline px PIGLET BASIS 2\% & & 1.980 & 1.980 & 1.980 & 1.980 \\
\hline DL-METHIONINE & & 0.162 & 0.203 & 0.168 & 0.208 \\
\hline L-LYSINE HCL & & 0.464 & 0.574 & 0.448 & 0.559 \\
\hline L-TRYPTOPHAN & & 0.177 & 0.308 & 0.177 & 0.308 \\
\hline L-THREONINE & & 0.167 & 0.203 & 0.165 & 0.201 \\
\hline CITRIC ACID ANHYDRATE & & 0.200 & 0.200 & 0.200 & 0.200 \\
\hline ILE-VAL BLEND (90-10) & & & 0.059 & & 0.056 \\
\hline VALINE $40 \% \mathrm{PX}$ & & 0.135 & 0.322 & 0.135 & 0.323 \\
\hline Nutrient & Unit & & & & \\
\hline Crude protein & $\%$ & 16.8 & 17.0 & 16.7 & 17.0 \\
\hline Crude fat Berntrop & $\%$ & 4.3 & 4.3 & 7.6 & 7.6 \\
\hline Crude fat & $\%$ & 3.5 & 3.5 & 6.8 & 6.8 \\
\hline Crude fibre & $\%$ & 4.9 & 4.9 & 4.9 & 4.9 \\
\hline Ash & $\%$ & 4.9 & 4.9 & 5.1 & 5.1 \\
\hline Moisture & $\%$ & 9.9 & 9.9 & 9.5 & 9.5 \\
\hline Dry matter & $\%$ & 90.1 & 90.1 & 90.5 & 90.5 \\
\hline Starch Ewers & $\%$ & 39.9 & 39.6 & 37.2 & 36.8 \\
\hline Sugar & $\%$ & 5.3 & 5.3 & 5.3 & 5.3 \\
\hline NE swine & MJ & 10.12 & 10.12 & 10.82 & 10.82 \\
\hline EW & - & 1.15 & 1.15 & 1.23 & 1.23 \\
\hline dP standard swine & $\%$ & 0.37 & 0.37 & 0.39 & 0.39 \\
\hline sid LYS sw & $\%$ & 1.06 & 1.15 & 1.06 & 1.15 \\
\hline sid MET sw & $\%$ & 0.39 & 0.43 & 0.39 & 0.43 \\
\hline sid CYS sw & $\%$ & 0.25 & 0.25 & 0.25 & 0.25 \\
\hline sid $M+C$ sw & $\%$ & 0.64 & 0.68 & 0.64 & 0.68 \\
\hline sid THR sw & $\%$ & 0.70 & 0.74 & 0.70 & 0.74 \\
\hline sid TRP sw & $\%$ & 0.21 & 0.24 & 0.21 & 0.24 \\
\hline sid VAL sw & $\%$ & 0.75 & 0.83 & 0.75 & 0.83 \\
\hline sid ARG sw & $\%$ & 0.89 & 0.89 & 0.90 & 0.90 \\
\hline sid ISO sw & $\%$ & 0.59 & 0.64 & 0.59 & 0.64 \\
\hline sid LEU sw & $\%$ & 1.07 & 1.07 & 1.07 & 1.07 \\
\hline sid HIS sw & $\%$ & 0.36 & 0.36 & 0.36 & 0.36 \\
\hline sid P+T sw & $\%$ & 1.24 & 1.24 & 1.24 & 1.24 \\
\hline sid PHE sw & $\%$ & 0.72 & 0.72 & 0.72 & 0.72 \\
\hline sid TYR sw & $\%$ & 0.52 & 0.52 & 0.52 & 0.52 \\
\hline sid MET/LYS sw & - & 0.37 & 0.37 & 0.37 & 0.38 \\
\hline sid CYS/LYS sw & - & 0.24 & 0.22 & 0.24 & 0.22 \\
\hline sid $M+C / L Y S$ sw & - & 0.61 & 0.59 & 0.61 & 0.59 \\
\hline sid THR/LYS sw & - & 0.66 & 0.64 & 0.66 & 0.64 \\
\hline
\end{tabular}




\begin{tabular}{|c|c|c|c|c|c|}
\hline sid TRP/LYS sw & - & 0.20 & 0.21 & 0.20 & 0.21 \\
\hline sid VAL/LYS sw & - & 0.71 & 0.72 & 0.71 & 0.72 \\
\hline sid ARG/LYS sw & - & 0.84 & 0.77 & 0.85 & 0.78 \\
\hline sid ISO/LYS sw & - & 0.56 & 0.56 & 0.56 & 0.56 \\
\hline sid LEU/LYS sw & - & 1.02 & 0.94 & 1.02 & 0.94 \\
\hline sid HIS/LYS sw & - & 0.34 & 0.31 & 0.34 & 0.31 \\
\hline 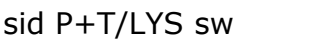 & - & 1.17 & 1.08 & 1.17 & 1.08 \\
\hline LYS - Lysine & $\%$ & 1.15 & 1.24 & 1.15 & 1.24 \\
\hline MET - Methionine & $\%$ & 0.41 & 0.46 & 0.42 & 0.46 \\
\hline CYS - Cystine & $\%$ & 0.29 & 0.29 & 0.29 & 0.29 \\
\hline$M+C-$ Met + Cys & $\%$ & 0.71 & 0.75 & 0.71 & 0.75 \\
\hline THR - Threonine & $\%$ & 0.77 & 0.81 & 0.77 & 0.81 \\
\hline TRP - Tryptophan & $\%$ & 0.24 & 0.27 & 0.24 & 0.27 \\
\hline ISO - Isoleucine & $\%$ & 0.66 & 0.71 & 0.66 & 0.71 \\
\hline PHE - Phenylalanine & $\%$ & 0.80 & 0.80 & 0.81 & 0.81 \\
\hline HIS - Histidine & $\%$ & 0.40 & 0.40 & 0.40 & 0.40 \\
\hline LEU - Leucine & $\%$ & 1.22 & 1.22 & 1.22 & 1.22 \\
\hline TYR - Tyrosine & $\%$ & 0.57 & 0.57 & 0.57 & 0.57 \\
\hline VAL - Valine & $\%$ & 0.84 & 0.92 & 0.84 & 0.92 \\
\hline Calcium & $\%$ & 0.55 & 0.55 & 0.59 & 0.59 \\
\hline Phosphor tot & $\%$ & 0.44 & 0.44 & 0.47 & 0.47 \\
\hline Sodium & $\%$ & 0.25 & 0.25 & 0.25 & 0.25 \\
\hline Chlorine & $\%$ & 0.53 & 0.55 & 0.53 & 0.55 \\
\hline Potassium & $\%$ & 0.69 & 0.69 & 0.69 & 0.69 \\
\hline $\mathrm{Cu}$ tot & $\mathrm{mg} / \mathrm{kg}$ & 141 & 141 & 141 & 141 \\
\hline Zn tot & $\mathrm{mg} / \mathrm{kg}$ & 138 & 138 & 137 & 137 \\
\hline Mn tot & $\mathrm{mg} / \mathrm{kg}$ & 53 & 53 & 52 & 52 \\
\hline Vit A & $\mathrm{IU} / \mathrm{kg}$ & 16000 & 16000 & 16000 & 16000 \\
\hline Vit D3 & $\mathrm{IU} / \mathrm{kg}$ & 1000 & 1000 & 1000 & 1000 \\
\hline Vit E & $\mathrm{mg} / \mathrm{kg}$ & 100 & 100 & 100 & 100 \\
\hline
\end{tabular}




\section{Appendix 3 Analysed nutrient composition of the experimental diets $(\mathrm{g} / \mathrm{kg})$}

\begin{tabular}{|c|c|c|c|c|c|c|c|c|}
\hline & \multicolumn{4}{|c|}{ Weaner diet } & \multicolumn{4}{|c|}{ Starter diet } \\
\hline & Control & $+\mathrm{AA}$ & + Energy & +AA+Energy & Control & $+A A$ & + Energy & +AA+Energy \\
\hline Dry matter & 922 & 924 & 925 & 918 & 911 & 911 & 907 & 908 \\
\hline Ash & 50 & 49 & 53 & 48 & 45 & 45 & 45 & 46 \\
\hline Crude protein & 165 & 167 & 173 & 170 & 170 & 166 & 160 & 165 \\
\hline Crude fat & 48 & 45 & 86 & 82 & 38 & 38 & 69 & 67 \\
\hline Crude fibre & 52 & 54 & 44 & 43 & 41 & 42 & 48 & 44 \\
\hline Starch & 366 & 364 & 331 & 347 & 387 & 383 & 349 & 357 \\
\hline Sugars & 71 & 69 & 80 & 71 & 63 & 64 & 61 & 62 \\
\hline LYS & 11.92 & 12.80 & 12.76 & 13.02 & 11.60 & 12.50 & 11.41 & 12.42 \\
\hline MET & 4.19 & 4.72 & 4.09 & 4.61 & 4.03 & 4.59 & 4.21 & 4.29 \\
\hline CYS & 3.08 & 3.04 & 3.10 & 2.93 & 2.95 & 2.98 & 2.89 & 2.82 \\
\hline THR & 7.69 & 8.10 & 8.06 & 8.02 & 7.52 & 7.79 & 7.85 & 7.71 \\
\hline TRP & 2.58 & 2.85 & 2.60 & 2.83 & 2.58 & 2.76 & 2.59 & 2.70 \\
\hline ILE & 6.80 & 7.54 & 7.28 & 7.27 & 6.77 & 7.26 & 6.82 & 7.13 \\
\hline ARG & 9.88 & 9.83 & 10.59 & 9.49 & 9.38 & 9.78 & 9.71 & 9.77 \\
\hline PHE & 8.00 & 8.19 & 8.43 & 7.76 & 7.81 & 8.07 & 7.96 & 7.92 \\
\hline HIS & 4.44 & 4.40 & 4.73 & 4.23 & 4.21 & 4.18 & 4.21 & 4.51 \\
\hline LEU & 12.01 & 12.16 & 12.69 & 11.72 & 11.92 & 11.99 & 11.76 & 12.01 \\
\hline TYR & 5.95 & 6.16 & 6.32 & 6.07 & 5.89 & 6.02 & 6.43 & 6.24 \\
\hline VAL & 8.62 & 9.54 & 8.86 & 9.22 & 8.15 & 9.14 & 8.22 & 9.09 \\
\hline ALA & 6.92 & 7.15 & 7.30 & 6.82 & 6.72 & 6.96 & 6.71 & 6.83 \\
\hline ASP & 14.30 & 14.63 & 15.66 & 14.02 & 13.73 & 13.97 & 14.05 & 14.09 \\
\hline GLU & 31.75 & 31.72 & 32.20 & 30.47 & 31.42 & 32.01 & 30.98 & 31.28 \\
\hline GLY & 7.02 & 7.12 & 7.29 & 6.88 & 6.88 & 6.98 & 6.91 & 6.94 \\
\hline PRO & 10.75 & 11.54 & 11.18 & 11.28 & 10.17 & 12.40 & 11.04 & 10.93 \\
\hline SER & 7.82 & 7.90 & 8.18 & 7.54 & 7.62 & 7.64 & 7.54 & 7.70 \\
\hline \multicolumn{9}{|c|}{ Pellet hardness $\left(\mathrm{kg} / \mathrm{cm}^{2}\right)$} \\
\hline - factory & 3.3 & 3.6 & 2.4 & 1.9 & 4.8 & 5.0 & 2.4 & 2.4 \\
\hline - lab & 5.3 & 4.4 & 2.8 & 2.3 & 4.9 & 5.4 & 3.3 & 3.2 \\
\hline \multicolumn{9}{|l|}{ Durability (\%) } \\
\hline - factory & 91.4 & 89.2 & 80.6 & 76.6 & 90.3 & 93.0 & 78.6 & 81.6 \\
\hline$-1 a b$ & 92.3 & 89.6 & 84.0 & 79.4 & 88.6 & 90.7 & 76.3 & 81.1 \\
\hline
\end{tabular}




\section{Appendix 4 Room temperature}

\section{Hourly room temperature in batch 1 to 4 on Farm A}
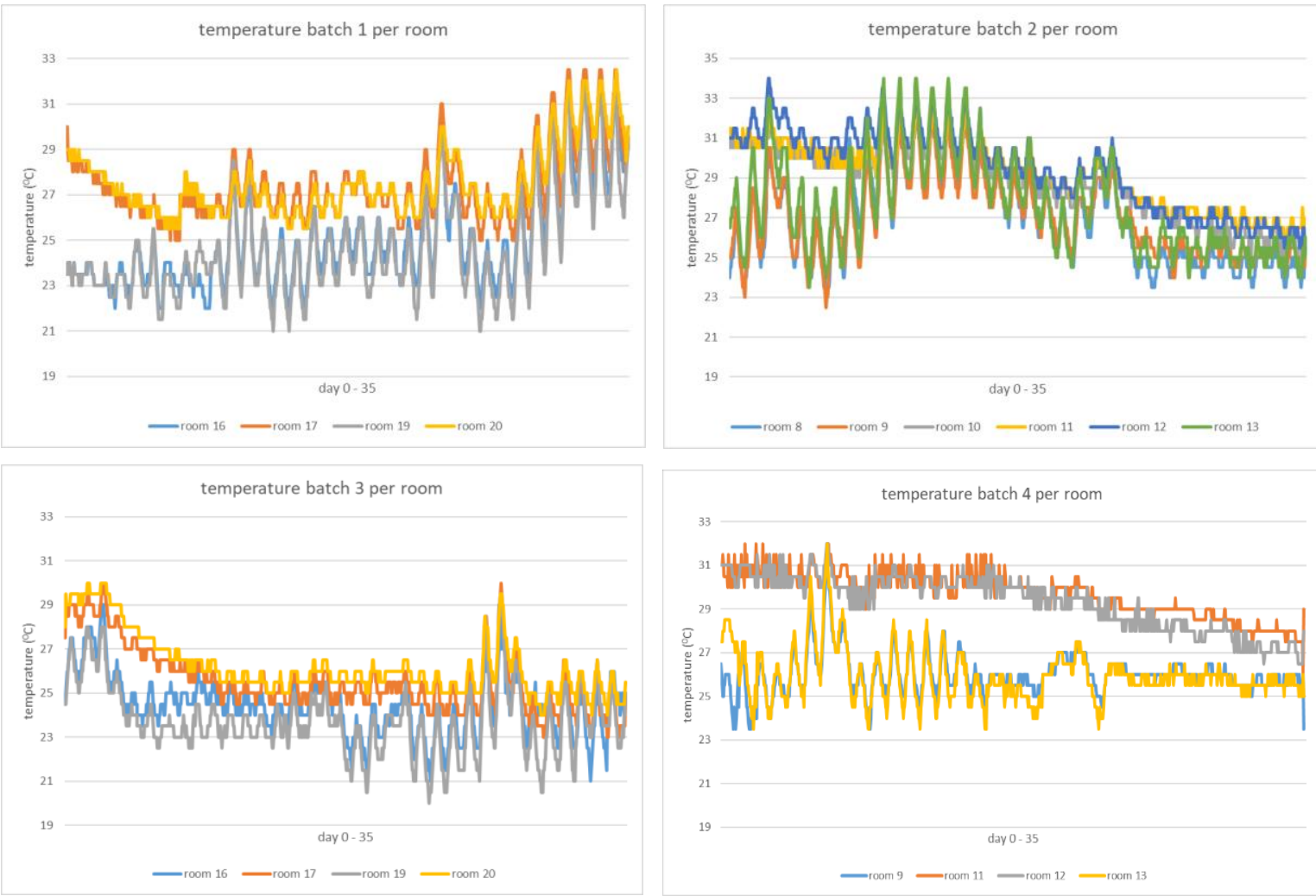

Mean room temperature, relative air humidity and level of $\mathrm{CO}_{2}$ in batch 1 and 2 on Farm $\mathrm{B}$

\begin{tabular}{|c|c|c|c|c|}
\hline & $\begin{array}{c}\text { Batch } 1 \\
\text { HSC }\end{array}$ & $\begin{array}{c}\text { Batch } 1 \\
\text { LSC }\end{array}$ & $\begin{array}{c}\text { Batch } 2 \\
\text { HSC }\end{array}$ & $\begin{array}{c}\text { Batch } 2 \\
\text { LSC }\end{array}$ \\
\hline mean temperature $\left({ }^{\circ} \mathrm{C}\right)$ & 27.5 & 25.9 & 26.3 & 25.0 \\
\hline sd temperature $\left({ }^{\circ} \mathrm{C}\right)$ & 1.6 & 1.7 & 0.8 & 1.1 \\
\hline minimum temperature $\left({ }^{\circ} \mathrm{C}\right)$ & 24.9 & 22.9 & 24.7 & 22.1 \\
\hline maximum temperature $\left({ }^{\circ} \mathrm{C}\right)$ & 33.6 & 32.9 & 29.4 & 29.7 \\
\hline mean air humidity (\%) & 64.1 & 63.1 & 66.6 & 65.7 \\
\hline sd air humidity (\%) & 5.3 & 5.9 & 4.6 & 5.3 \\
\hline minimum air humidity (\%) & 46.0 & 45.0 & 54.8 & 47.0 \\
\hline maximum air humidity (\%) & 79.0 & 80.0 & 79.0 & 85.0 \\
\hline mean $\mathrm{CO}_{2}$ & 1595 & 1330 & 1795 & 1573 \\
\hline $\mathrm{sd} \mathrm{CO}_{2}$ & 308 & 277 & 225 & 284 \\
\hline minimum $\mathrm{CO}_{2}$ & 779 & 493 & 1126 & 642 \\
\hline maximum $\mathrm{CO}_{2}$ & 2729 & 2419 & 2511 & 2625 \\
\hline
\end{tabular}



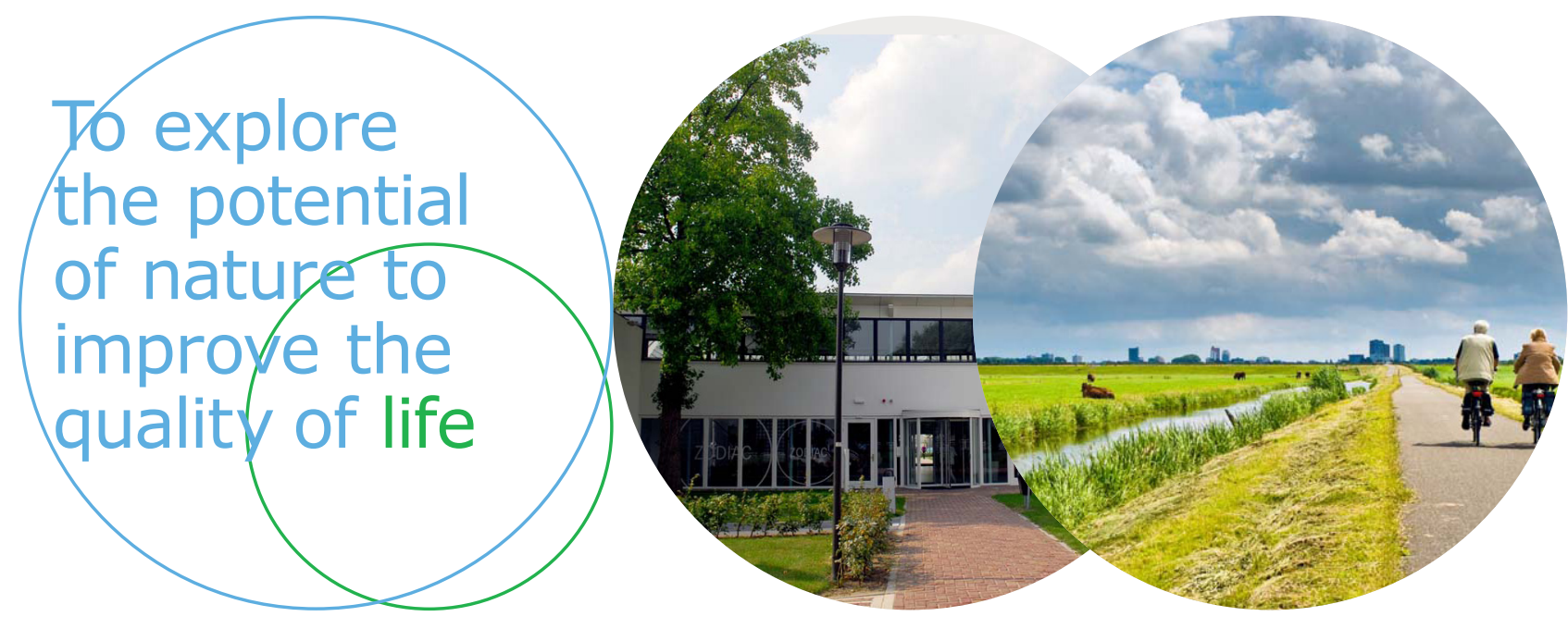

Wageningen Livestock Research P.O. Box 338

6700 AH Wageningen

The Netherlands

$\mathrm{T}+31(0) 317483953$

E info.livestockresearch@wur.nl

www.wur.nl/livestock-research

Wageningen Livestock Research creates science based solutions for a sustainable and profitable livestock sector. Together with our clients, we integrate scientific knowledge and practical experience to develop livestock concepts for future generations.

Wageningen Livestock Research is part of Wageningen University \& Research. Together we work on the mission: 'To explore the potential of nature to improve the quality of life'. A staff of 6,500 and 10,000 students from over 100 countries are working worldwide in the domain of healthy food and living environment for governments and the business community-at-large. The strength of Wageningen University \& Research lies in its ability to join the forces of specialised research institutes and the university. It also lies in the combined efforts of the various fields of natural and social sciences. This union of expertise leads to scientific breakthroughs that can quickly be put into practice and be incorporated into education. This is the Wageningen Approach. 